Portland State University

PDXScholar

$11-23-1981$

\title{
The Determination of a Relative Chronology for a Surface Archeological Site Using the Obsidian Hydration Dating Method
}

Scott Preston Thomas

Portland State University

Follow this and additional works at: https://pdxscholar.library.pdx.edu/open_access_etds

Part of the Archaeological Anthropology Commons, and the Earth Sciences Commons Let us know how access to this document benefits you.

\section{Recommended Citation}

Thomas, Scott Preston, "The Determination of a Relative Chronology for a Surface Archeological Site Using the Obsidian Hydration Dating Method" (1981). Dissertations and Theses. Paper 3134.

https://doi.org/10.15760/etd.3126

This Thesis is brought to you for free and open access. It has been accepted for inclusion in Dissertations and Theses by an authorized administrator of PDXScholar. Please contact us if we can make this document more accessible: pdxscholar@pdx.edu. 
AN ABSTRACT OF THE THESIS OF Scott Preston Thomas for the Master of Arts in Anthropology presented November 23, 1981.

Title: The Determination of a Relative Chronology for a Surface Archeological site Using the Obsidian Hydration Dating Method.

APPROVED BY MEMBERS OF THE THESIS COMMITTEE:

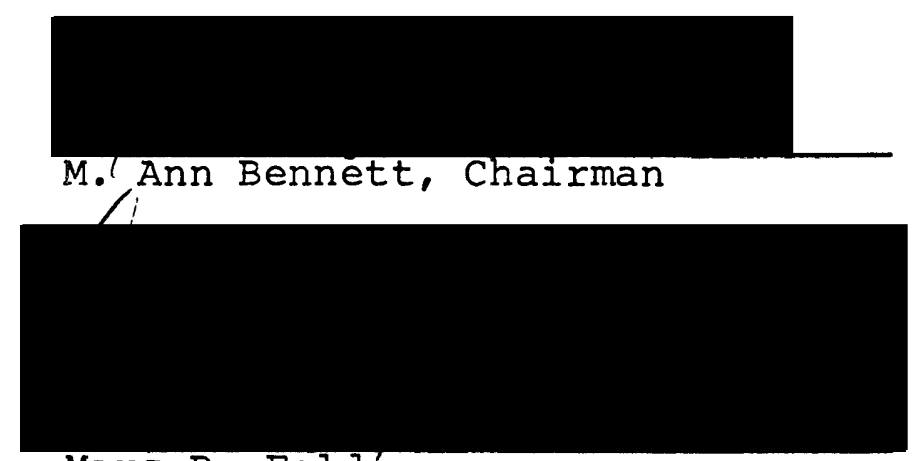

Marc R. Feldésman
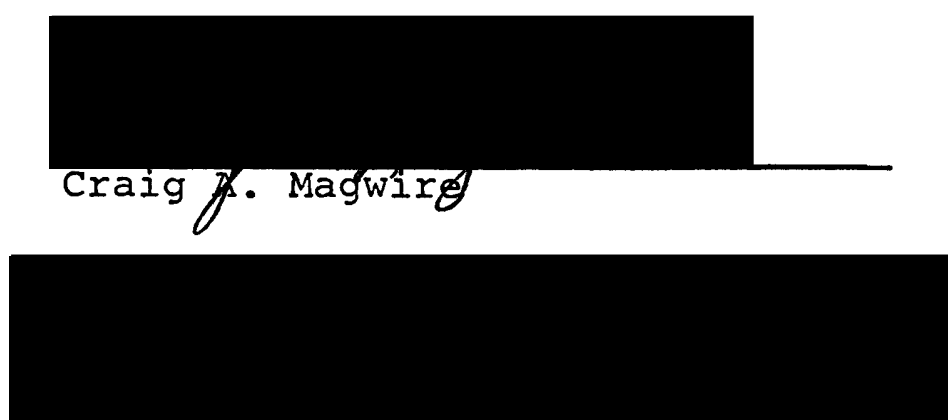

Jarvin $\mathrm{H} \cdot$ Beeson

This methodological study is an attempt to develop relative chronologies for surface archeological sites from the obsidian hydration analysis of waste flake samples. 
Two sites in southeastern oregon were selected and their surface components sampled. The results of the obsidian hydration analysis indicate, that with the use of random sampling methods and general geochemical control, a fairly accurate representation of the history of an archeological surface site can be obtained. 
THE DETERMINATION OF A RELATIVE CHRONOLOGY FOR A SURFACE ARCHEOIOGICAL SITE USING THE OBSIDIAN HYDRATION DATING METHOD

by

SCOTT PRESTON THOMAS

A thesis submitted in partial fulfillment of the requirements for the degree of

\author{
MASTER OF ARTS \\ in \\ ANTHROPOLOGY
}

Portland State University

1982 
TO THE OFFICE OF GRADUATE STUDIES AND RESEARCH:

The members of the committee approve the thesis of Scott Preston Thomas presented 23 November 1981.

M. Ann Bennett, Chairman
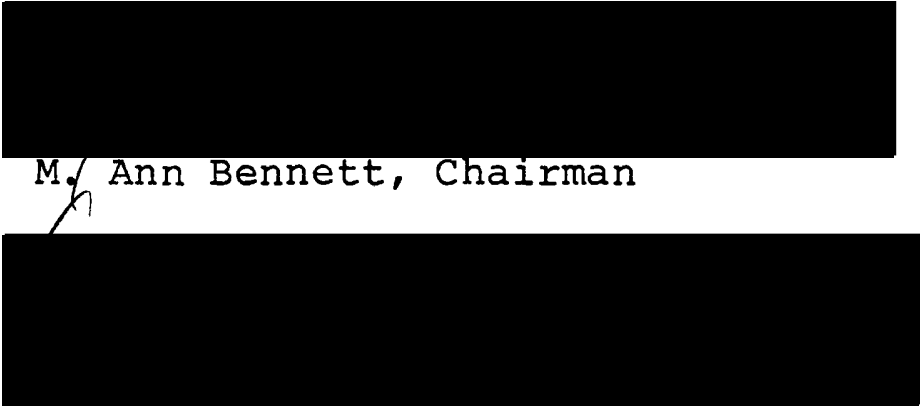

Marc R. Feldesman

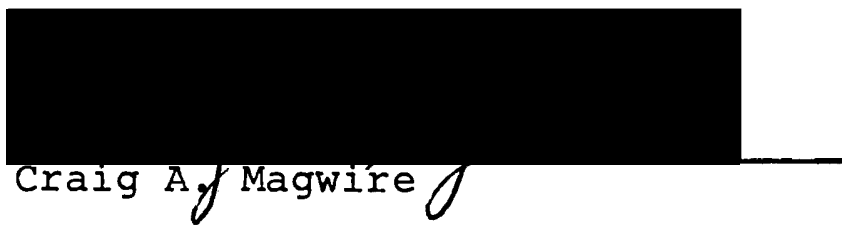

xarvin $H$. Beeson

APPROVED :

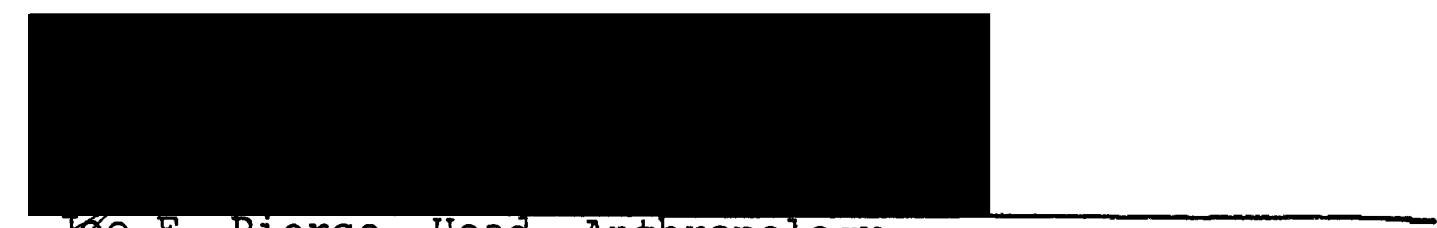

yoe E. Pierce, Head, Anthropology

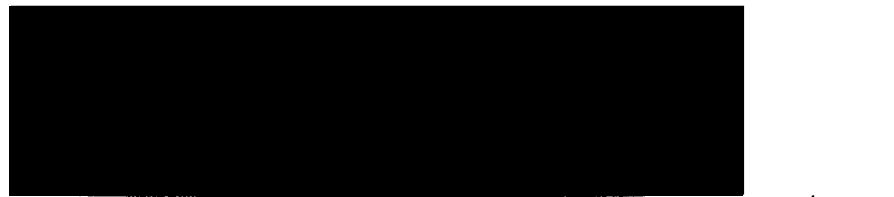

Stanley E. Rauch, Dean of Graduate studies and Research 


\section{ACKNOWLEDGEMENTS}

I would like to take this opportunity to thank all of the people who helped me in many ways to produce this document. I am indebted to Tom Newman for stimulating my interest in obsidian hydration dating and its applications. Special thanks go to Todd Thomas and Fred Gullixsen for their advice and counsel while $I$ was researching and writing this thesis. Also helpful for their archeological and geological advice were M. Ann Bennett and Marv Beeson. I would like to thank Barb Portwood and Virginia Pfaff for their patience with me while I was measuring hyaration rinds in the hot summer evenings of 1980. Last, but not least, many thanks to my family and friends for their patience and support during the years it took to complete this research project. 
TABLE OF CONTENTS

PAGE

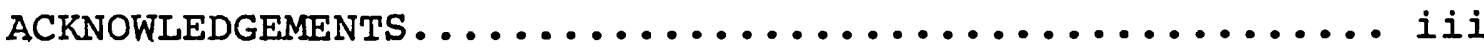

LIST OF TABLES............................ vii

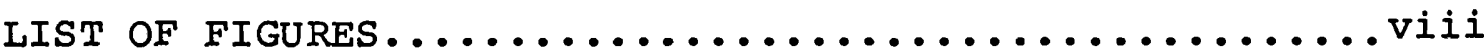

CHAPTER

I INTRODUCTION......................... 1

General Review of Method............... 1

Review of Previous Research............. 2

statement of Purpose................. 3

II THEORY ............................ 5

Sources of Hydration Measurement

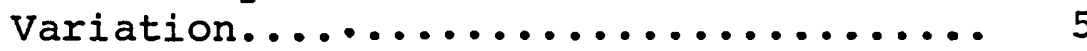

Chemical Composition............... 5

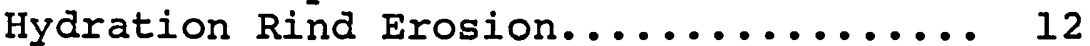

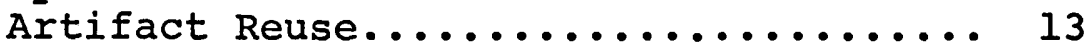

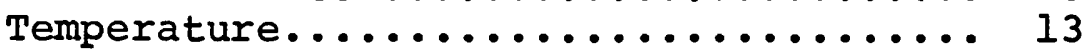

II $\quad$ PROCEDURES ............................ 20

Site Selection.................... 20

Site Selection Criteria and

Discussion.................... 20

Site Descriptions.................. 22

View Point site (MNWR 121).......... 22

Stinking Lake Site (MNWR 132) ........ 25

Sample Selection................. 28 


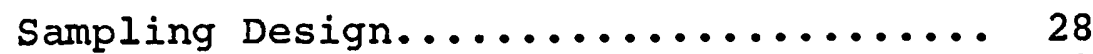

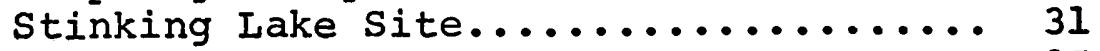

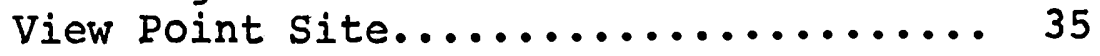

Projectile Points.................. 36

Their Function in This study......... 36

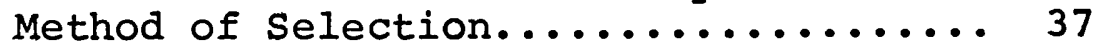

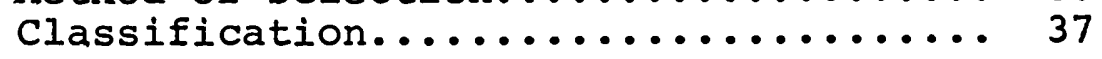

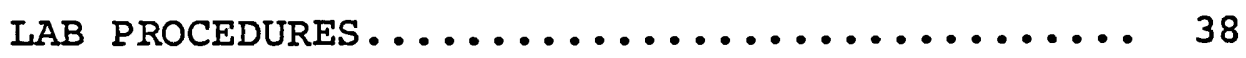

Preparing the Thin Sections........... 38

Measuring the Hydration Rind Thickness... 39

Measurement Error................... 42

Preparation of Samples for Index of Refraction Measurements............

Measurement of the Index of

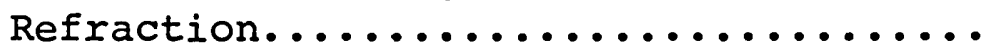

Hydration Data..................... 46

Flakes............................... 46

Projectile Points from stinking lake

Site (MNWR 132).................

Projectile Points from View Point

Site (MNWR I2l)............... 52

Index of Refraction................ 57

Flakes and Projectile Points......... 57

V DISCUSSION............................ 63

Hydration Data: Flakes............... 63

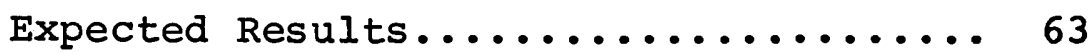

Observed Results................... 64

Statistical Test of the Hydration Data.... 69 Absence of a Measureable Hydration Rind.... 74 
Presence of Two Eydration Values.......... 74

Large Variation of Hydration Values

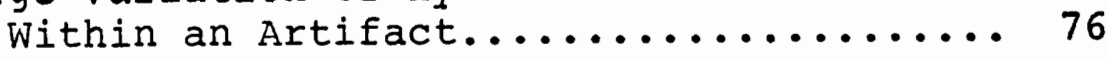
Index of Refraction................. 77

Flakes............................. 80

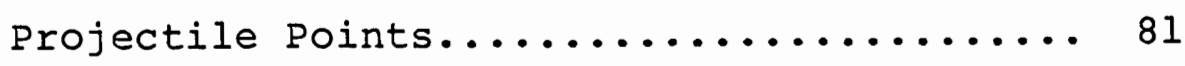

Chronological sequence by Type........ 81

Comparison of Typological sequence and Hydration Data................ 84

VI SUMMARY AND CONCLUSIONS................ 88 BIBLIOGRAPHY ............................... 92

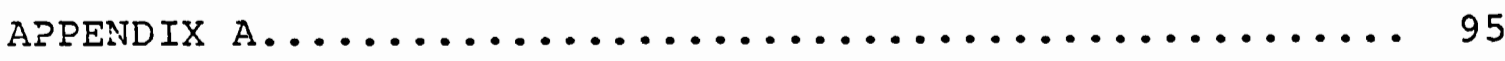

Projectile Points: Classification........ 95

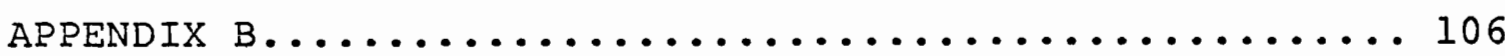




\section{LIST OF TABLES}

TABLE

PAGE

I Major Mineral Chemistry of Two Obsidian

samples...........................

II Tabular Display of Five Collection Grids

and Their Hydration Values from stinking

Lake Site (MNWR 132)

II Compositional Parameters for Samples 0-12

and $0-53$

IV Examples of Artifact Reuse and Wind

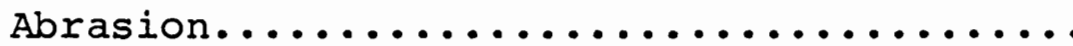

V Comparison of Artifact Typological Sequence with Obsidian Hydration Sequence.......... 


\section{IIST OF FIGURES}

FIGURE

PAGE

1 Illustration of the Hypothetical Effects of Differences in Chemical Composition Upon Hydration Rate and Resulting Rind Thicknesses of Two Contemporaneous Artifacts... Demonstration of the Hypothetical Effects of Differential Intrasite Geomorphic Activity Upon the Hydration Rate and Resulting Thicknesses of Two Contemporaneous Àrtifacts. Site Area Map: Stinking Lake Site

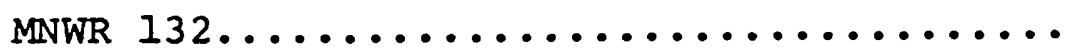

From Stinking Lake Site MNWR 132 to

Illustrate Sampling Design............ 32 Hydration Rind Thickness (with Standard

Deviations) vs. Frequency: Flakes and

Projectile Points.................... 
10 Hydration Thickness ( $\mu$ ) vs. Frequency -

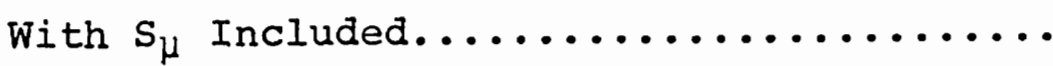

11-A S.L.P. 2 - Elko Eared, 5.27 Microns........ 53

11-B S.I.P. I - Fluted Foint, 8.45 Microns....... 53

11-C V.P. 62 - Humboldt Concave Base ......... 53

Il-D S.L.P. 4 - Type 2E (Fagan 1974), 4.36

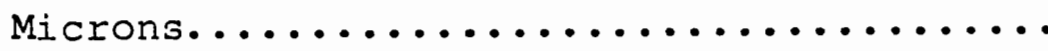

Il-E S.L.P. 5 - Type 7C (Fagan 1974), lJo Rind

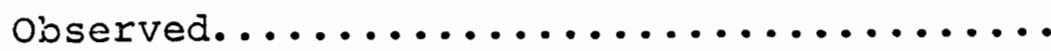

11-F V.P.P. I - Elko Eared, 6.26 and 8.84

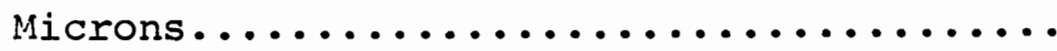

II-G S.L.P. 6 - Type 3 or Haskett (Layton 1972),

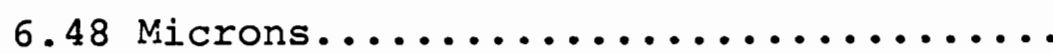

II-H S.L.P. 12 - Northern Side-notched, No

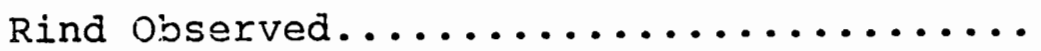

11-I S.L.P. 10 - Pinto Square Shoulder, 4.11

Microns......................

II-J S.L.P. 9 - Type 9 (Layton 1972), 5.09

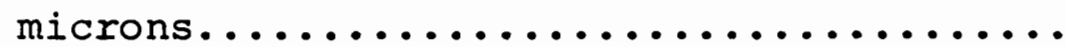

11-K S.L.P. 8 - Northern Side-notched, iNo Rind

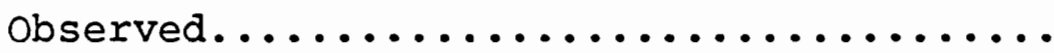

11-L S.L.P. 11- Great Basin Transverse, 5.41

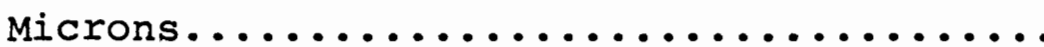

11-M S.L.P. 7 - Type 3 or Haskett Type (Layton

1972)，4.22 Microns................. 
11-N S.L.P. 13 - Type 5A (Fagan 1974), Not

Analyzed........................... 55

11-O S.L.P. 14 - Rose Spring Corner-notched,

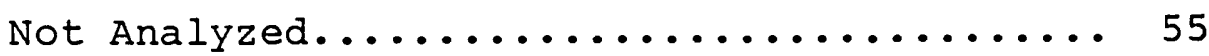

11-P S.L.P. 15 - Fype 2F (Fagan 1974), Not

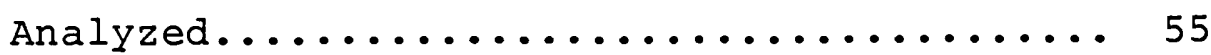

12 Plot of Hydration Rind Thickness vs. Fre-

quency for Projectile Points Analyzed

from MNWR $132 \ldots \ldots \ldots \ldots \ldots \ldots \ldots \ldots \ldots \ldots$

13 Plot of Index of Refraction $v s$. Hydration

Rind width for View point Chipping

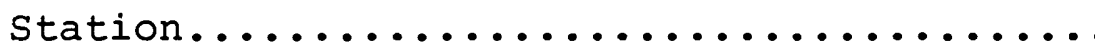

14 Plot of Index of Refraction $v s$. Hydration

Rind width for Stinking lake Fabitation

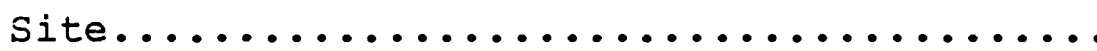

15 Plot of Index of Refraction for Four Samples

Donated by Marvin Beeson, Ph.D........... 61

16 Eydration Rind Thickness vs. Frequency.......66 66

17 Hydration Rind Thickness vs. Frequency........ 67

18 Hydration Rind Thickness $v s$. Frequency........68 68

19 Runs Test Computations and Results for

MNWR 132 and MNWR 121 Data.............. 71

20 Affects of Data Array Length or Area Upon

Randomness: Two Hypothetical Examples..... 
21 Hypothetical Illustration of the Effects of Intrasite Differential Geological Activity Coupled with Differences in Chemical Composition, Upon Hydration Rate and Resulting Rind Thicknesses of Two Contemporaneous Artifacts. 
CHAPTER I

INTRODUCTION

General Review of Method

The obsidian hydration dating method, first proposed and developed by Friedman and Smith (1960), is based on the fact that nonhydrated obsidian (a volcanic glass) will absorb water from the surrounding atmosphere. This fact is well known in both geological and archeological circles, but the process by which hydration occurs is not. The process is quite slow (microns/thousands of years) and its rate is dependent upon the environmental temperature (Friedman and Smith 1960; Friedman and Long 1976) and the chemical composition of the obsidian (Aiello 1969; Friedman and Long 1976). The distance water migrates into the interior of the obsidian can be measured with the aid of a light microscope, as there is an observable migration front (this zone of hydration is referred to as the "hydration rind"). The thickness of the hydration rind represents the length of time since the surface of the obsidian has been flaked. The relatively simple and inexpensive process by which the hydration rind can be measured has stimulated the use of obsidian hydration analysis as an archeological dating tool. 
Review of Previous Research

However, hydration dating is not problem-free, as many investigators have become acutely aware since 1960 . Unfortunately, the rate of hydration must be assumed to be constant from the time of artifact manufacture to its eventual study by an archeologist in order to attain an absolute date for an artifact. Such an assumption is rarely, if ever, borne out in nature and the best the archeologist can hope for is a situation where the effects of temperature (which controls the rate of hydration) fluctuations are minimal (assuming chemical homogeneity between obsidian samples). Because these flucuations, both annual and diurnal, are minimal at depths of over $20 \mathrm{~cm}$ below ground surface, buried obsidian artifacts are preferred for hydration studies. Most studies in obsidian hydration dating have been centered on absolute dates and buried artifacts (Layton 1972; Meighan, Foote and Aiello 1965; Johnson 1969; Fagan 1974). In response to the deficiencies of earlier studies, many investigators (Ericson 1978; Bowman, Asaro and Perlman 1973; Ericson and Kimberlin 1977) have concentrated on problems encountered in a hydration study when there are two or more chemically different obsidians included in the hydration sample, because such differences produce different hydration rates. Much emphasis has been placed on the need to characterize the different types of obsidian and their sources before ever attempting to inter- 
pret the hydration data. This emphasis is not misplaced and is the basis of criticism by investigators, well versed in geochemistry, to the majority of studies in which obsidian samples are assumed (not demonstrated) to be of homogeneous nature. To my knowledge, no one has done a thorough chemical analysis in combination with a hydration dating study. To do both requires a moderate budget, a large amount of time and the proper facilities.

Statement of Purpose

The purpose of this study is to determine if the relative chronology of an archeological surface site can be derived from a hydration analysis of a large sample of obsidian flakes. The study will deal with surface artifacts that are exposed to both diurnal and annual temperatures and, as a group, may or may not be chemically homogeneous. An attempt will be made (as discussed below) to estimate and/or minimize the effects upon the hydration data of these two variables: Southeast oregon was chosen as the general study area because obsidian is abundant there and there are many deflated surface sites available for study. In fact, one reason for the initiation of this study was an attempt to gain chronological information that is erased by the deflation process. If successful, this study will enable more information to be gathered from surface archeological sites than has been previously possible. It may also prove significant by adding a new dimension to the 
value of an obsidian waste flake, a common artifact seen in archeological sites of southeast oregon. More important, it may dispel the tendency for most investigators to treat surface scatters of obsidian as taboo entities in the realm of obsidian hydration dating. A quote from Meighan (1978)

illustrates a commonly held attitude toward surface obsidian, as an object of hydration study:

... On the other hand, surface obsidian, with a wide range of hydration readings, might be unusable for rate determinations even if the sample of individual pieces were large. Obsidian collected from the surface is not useless, but it is less trustworthy since surface pieces are subject to greater hazards of breakage, abrasion and deposition by casual visitors to the site, long after its major occupation has ceased. (Meighan 1978: 110) 
CHAPTER II

THEORY

Sources of Hydration Measurement Variation

The most obvious source of hydration thickness variation is relative age differences. The main objective of this study is to determine whether or not this primary source of variation can be seen as a relative chronology. However, relative differences in age, seen as a difference in hydration thickness, can be masked by other types of variation that are either inherent in the hydration process, external to that process, or a combination of both. Discussed below are the sources of "unwanted" variation that can obscure a relative chronology developed from a hydration analysis of obsidian waste flakes.

Chemical Composition. Friedman and Long (1976) reported that the hydration rate of obsidian is dependent upon its chemical composition. Although the relationship between different proportions of major elements in various obsidians and their effects upon the rate of hydration is not precisely known as yet, the authors have suggested three different parameters that are related to hydration rate. They note that the refractive index (a numerical representation of the ratio of the speed of light in an un- 
known substance compared to the speed of light in a vacuum) of a nonhydrated obsidian is inversely related to the hydration rate. On the other hand, the percent $\mathrm{SiO}_{2}$ (by weight) of an obsidian is directly related to its hydration rate. In more precise terminology, the hydration rate is related to the chemical composition of obsidian in the following manner (see also Table I): Obsidian samples with a relatively high $\mathrm{SiO}_{2}$ content tend to have greater amounts of $\mathrm{K}^{+}$ and smaller quantities of $\mathrm{Fe}^{2+}, \mathrm{Fe}^{3+}, \mathrm{Ca}^{2+}, \mathrm{Mg}^{2+}$, and $\mathrm{Na}^{+}$in their oxide form. High $\mathrm{SiO}_{2}$ obsidians also have a lower index of refraction and, according to Friedman and Long (1976), a faster hydration rate. The converse relationship, a relatively low $\mathrm{SiO}_{2}$ content with larger quantities of $\mathrm{Fe}$ $\mathrm{Ca}, \mathrm{Mg}$ and $\mathrm{Na}$ and smaller quantities of $\mathrm{K}$, results in a higher index of refraction and a slower hydration rate. Friedman and Smith (1960), in a discussion of the hydration rate of rhyolitic versus trachytic obsidian, concluded the opposite relationship. They indicated that trachytic obsidian from Egypt, a low silica, high iron and soda (Na) obsidian, hydrates at a much faster rate than rhyolitic obsidians in general. Unfortunately, they were not able to grind up the archeological specimens to make a precise chemical analysis. Nonetheless, it appears that Friedman, at least, has made an "about face" in light of the more precise and greater quantities of evidence available since 1960. His recently proposed hydration rate-chemical composition-index 


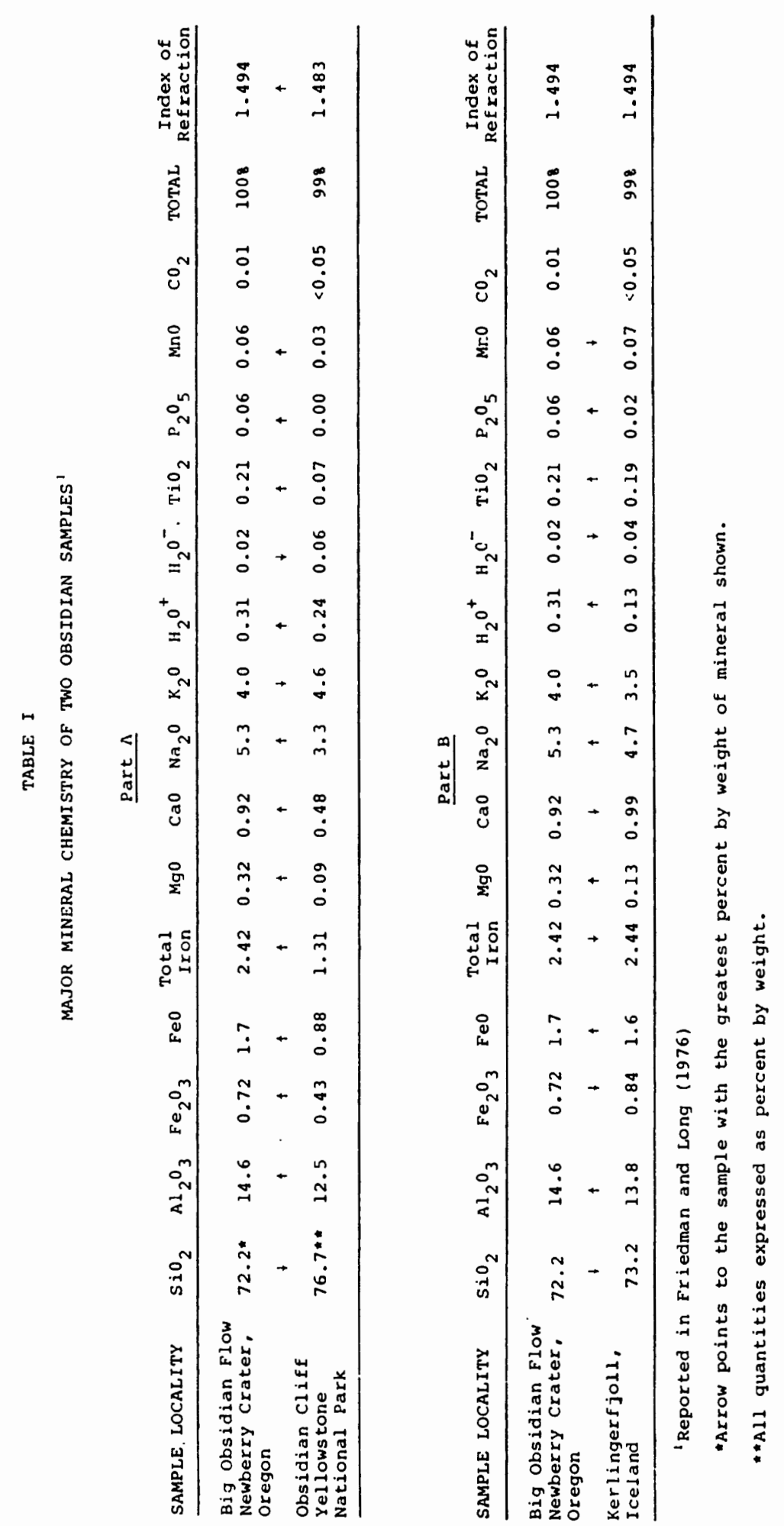


of refraction relationship is graphically displayed in Friedman and Long (1976:350). The graphs generally confirm the relationship, but their creditability depends upon the accuracy of the experimentally produced hydration rates for twelve geochemically distinct samples. A more direct indicator of the relationship between chemical composition and hydration rate is what Friedman and Long (1976) call the "chemical index," expressed as $\mathrm{SiO}_{2}-45(\mathrm{CaO}+\mathrm{MgO})-20\left(\mathrm{H}_{2} \mathrm{O}^{+}\right)$. This parameter is used to derive a hydration rate for a particular obsidian and is important when determining absolute dates. Important in this study is the knowledge that a resultant relative chronology, composed of hydration measurements, is a clear picture of the occupational history of an archeological site and not merely an illustration of the presence of a number of chemically different obsidians. It is known that obsidians vary in chemical composition between sources and within a particular source (Bowman, Asaro, and Perlman 1973). If the difference in chemical composition is great enough between obsidian sources, their hydration rates, under exposure to similar conditions, will be substantially different. This rate difference will introduce a false relative age difference (a hydration thickness difference) that may lead the investigator to an incorrect interpretation of the hydration results (Fig. 1).

Chemical composition was not strictly controlled in this study, for a number of reasons. The best way to inter- 


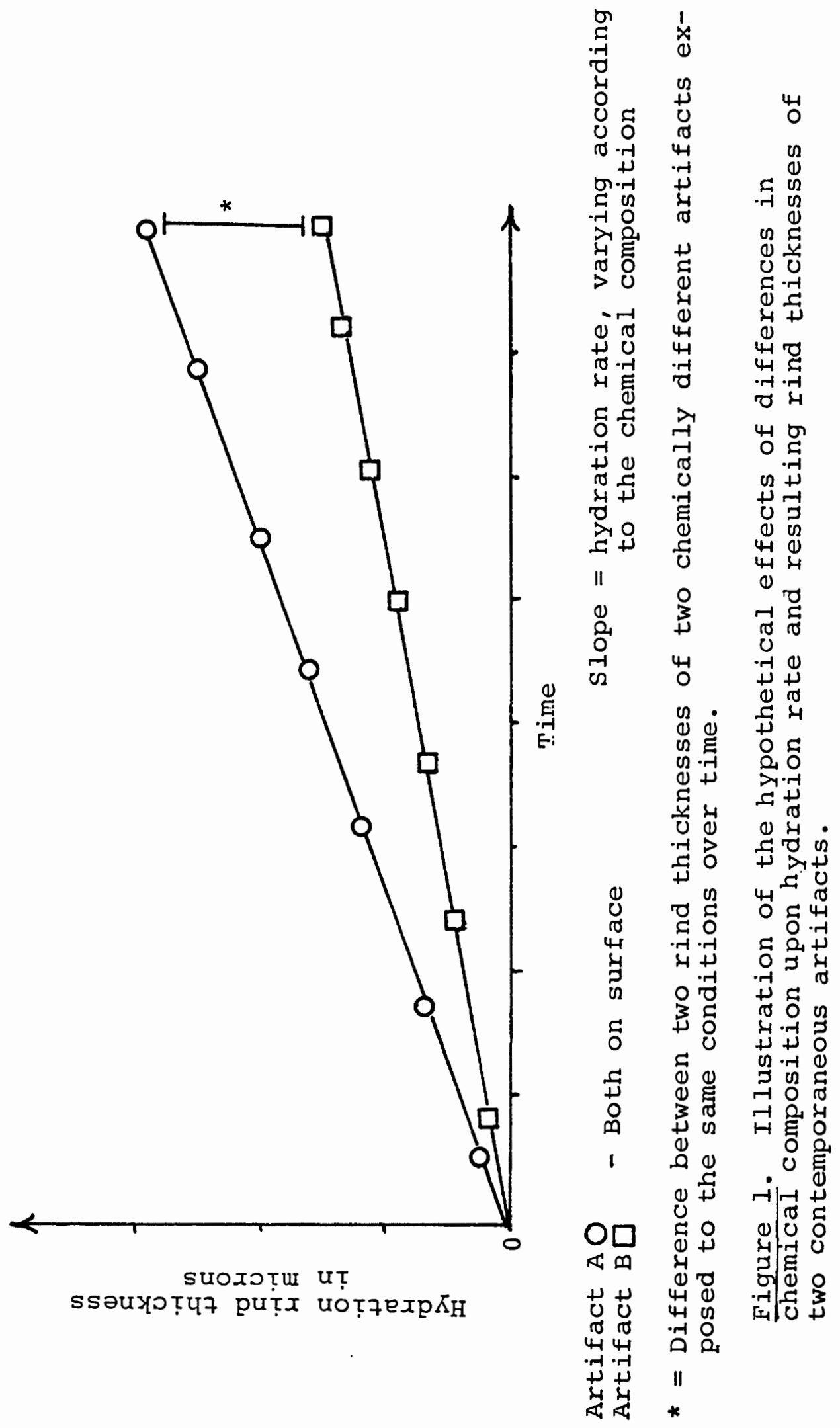


pret the hydration analysis data would be to know the chemical composition of every obsidian artifact included in the analysis. If this information were known, the artifacts with closely similar chemical compositions could be placed in groups, and each group of hydration data interpreted separately. This method would allow little, if any, variation in hyaration rind thickness (produced by dissimilar chemical composition) to obscure the thickness variation due to age differences. However, to have complete chemical composition data for each artifact included in this study would be costly and possibly inappropriate. Complete chemical analysis, including both trace and major element compositions, is especially important when empirically determined, local, hydration rates and absolute dates are the goals of a study. This study's primary goal was to establish a relative chronology for surface archeological sites from an array of hydration thickness data. No attempt was made to empirically determine either the hydration rate (microns/1000 years) or the absolute age of obsidian artifacts. Of interest were factors that cause differential hydration rates between obsidian samples to occur within an archeological site. Such a factor is chemical heterogeneity. Therefore, a preliminary measure of the degree of chemical homogeneity between obsidian samples submitted for hydration analysis was needed to estimate the effects of this variable.

A simple test, called the Becke line method of deter- 
mining the index of refraction, was performed on a number of samples from each archeological site. As stated above, Friedman and Long $(1976: 347,350)$ propose that the index of refraction of obsidian is inversely related to its hydration rate. A brief survey of the major element constituents (percent by weight) of twelve different obsidian samples (Friedman and Long, 1976:349) reveals that the index of refraction is inversely related to the $\mathrm{SiO}_{2}$ content by weight (Table I, Part A). Since the index of refraction is related to $\mathrm{SiO}_{2}$ content and they both are rough indicators of the hydration rate, the index of refraction test for chemical composition homogeneity is an appropriate test for a study of this kind. It should be mentioned here that two different obsidian samples, with different trace and major element compositions, can have the same index of refraction (Table I, Part B). As one can see, the two samples presented in Table I, Part'B have only slight chemical differences. Nonetheless, the index of refraction test for chemical composition homogeneity should not be utilized when attempting to determine a source area for an obsidian sample or when attempting to establish hydration rates for different obsidians in a specific geographical location. In this study the hydration thickness data from each site were graphically displayed. The distributions indicated that there were semi-discrete clusters of measurements that might represent relative age differences.

A sample from 
each of these clusters for each site was selected for index of refraction determinations. If all of the index of refraction tests resulted in the same index of refraction range, it could be concluded that the clusters of hydration thickness measurements were not due to chemical differences between samples.

Hydration Rind Erosion. In dry, semi-arid regions (for example, southeastern oregon) where vegetation is generally sparse and soil is loosely held, artifacts on the surface are susceptible to mechanical weathering by soilladen winds. An obsidian sample subjected to erosion on its upper surface may prove to have a substantially smaller hydration rind there than on its lower surface. A reduced rind thickness results in an erroneous hydration measurement that indicates the specimen is too young.

Control for the possible effects of wind erosion upon the upper surface of artifacts was easily accomplished in this study. Each flake was marked on its upper surface during the collection process and, when the thin sections were prepared for microscopic measurement of the hydration rind, the upper surface was again noted on the glass slides. When the hydration rinds were measured, readings from each surface were taken and the results compared. Any discrepancy in hydration thickness would be apparent at that time and could possibly be explained as the results of wind erosion. The actual occurrence of hydration rind erosion 
will be discussed below.

Artifact Reuse. An artifact that has been reused will sometimes show two different hydration rind thicknesses on the same or different surfaces, representing the two use events. If the original surface of an artifact has been completely removed during reuse, the first use event might not be recognized during analysis. However, fine cracks produced when the artifact was first used, will sometimes indicate the original age of the artifact (Friedman and Smith 1960).

Two or more different hydration rind measurements, attributed to the reuse of an obsidian artifact, would be observed and recorded, if encountered, during the hydration rind measurement process. If present, this phenomenon would be observed when taking readings on all of the surfaces of the obsidian artifacts. Artifact reuse is easily distinguished from the results of wind erosion because the hydration rinds in the reused area will have little thickness variation, whereas wind erosion will leave an irregular surface with a large amount of rind thickness variability.

Temperature. The environmental temperature, like chemical composition, is one of the two major variables that control the rate at which obsidian hydrates. Friedman and Long (1976) have done experimental tests with obsidian in controlled atmospheres over a four year period. They found hydration of obsidian, at temperatures from 95 to 245 
degrees C., proceeds at a rate that is proportional to the square root of time. All of this discussion is very straightforward, but quite misleading when considering surface deposited obsiaian samples. There are many factors that control the temperature surrounding the obsidian artifact, as discussed below.

First, and most important, we do not know how long obsidian artifacts have been on the surface. Therefore, the depositional history of an artifact, from manufacture to eventual study by an archeologist, is sometimes complex. Friedman and Long (1976) published some temperature measurements that were taken at various source areas of the obsidians they dealt with experimentally. In all of these locations they measured the temperature of obsidian pieces exposed to direct sunlight. In all locations but one, the temperature of the obsidian itself was $70 \%$ to $100 \%$ greater than the ambient air temperature and the hydration rate of obsidians at these locations was calculated to be triple that of buried obsidians. Layton (1973), in a cursory study of surface $v s$. buried projectile points, arrived at the conclusion that surface obsidian hydrates at twice the rate of buried obsidian. Although his sample size was quite small (27), no geochemisal tests were made on his samples, and he was dealing with artifacts (projectile points) that were used for moderately long time periods, this figure must be considered a conservative estimate. It is conservative 
because his "surface" projectile points may have, at one time, been buried and vice versa. In summary, buried and surface deposits of obsidian are subjected to widely different temperature regimes. Therefore, the real problem is determining the history of an archeological site (and its contents) that at present is a completely deflated surface site. Problems arise when one half of the site is buried under sand dunes and the other half has been eroded by a stream passing through it. The result is that obsidian on one half of the site is hyarating at a rate that is two to three times faster than the obsidian on the other half. If this condition is short term, the situation may be reversed and the effects of increased or decreased hydration rate may average out. If the dunes and small stream become established, the obsidians may hydrate at different rates for hundreds, perhaps thousands, of years. If conditions change and cause the site to become totally deflated, a surface site results. The end product of the geomorphological processes is two groups of obsidian (discarded at the same point in time) with substantially different hydration rind thicknesses (Fig. 2). The unknowing archeologist might interpret the two groups as being of different age and postulate two occupations of the site. The above intrasite geomorphological variation is most extreme in arid environments (of which southeast oregon is one) where soil is loosely held by sparse vegetation cover, and wind is a 

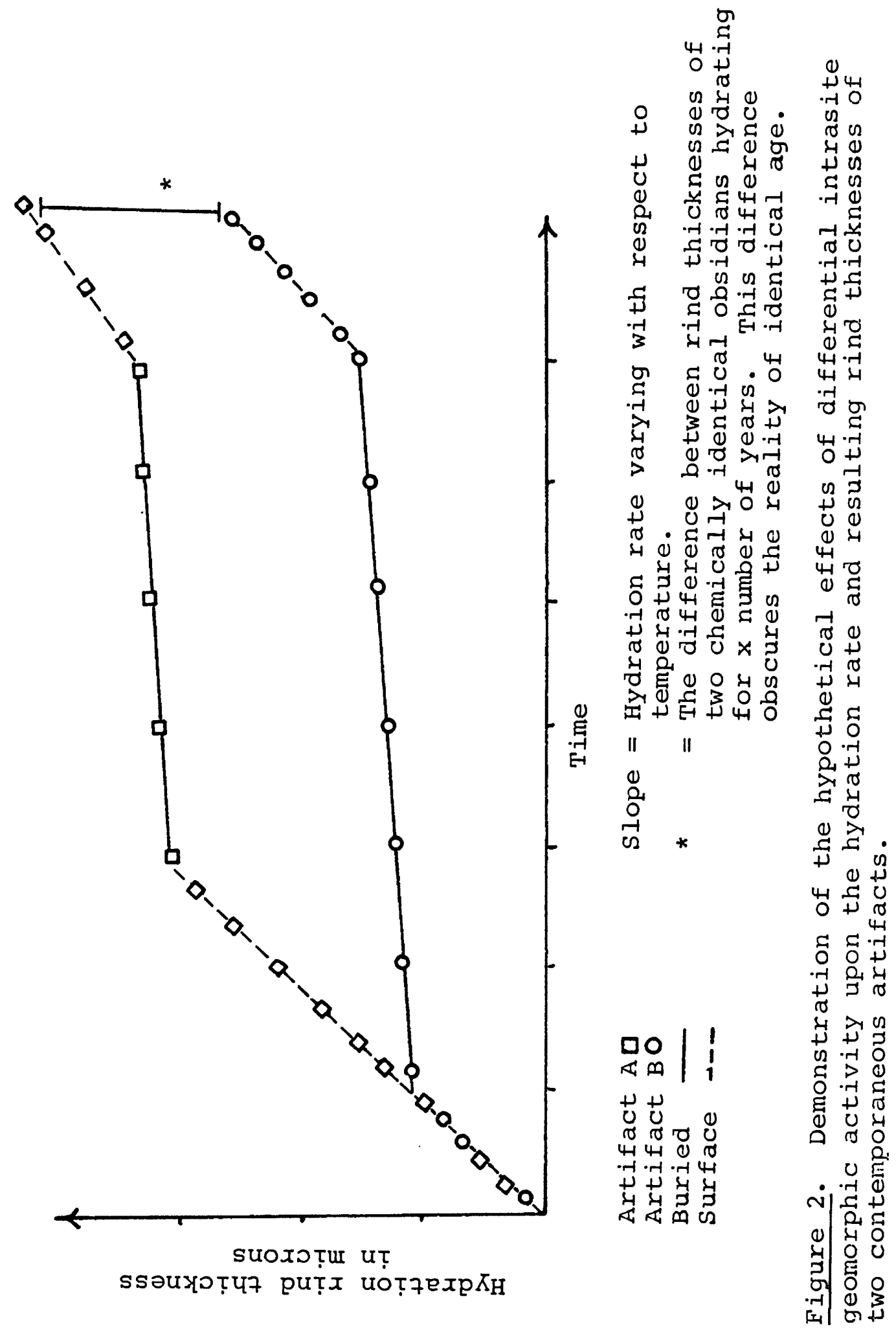
large contributor to erosion and deposition. The situation has been accentuated in the last 100 years by the introduction of livestock into the study area, resulting in large, deflated areas that are devoid of vegetation. Issentially, the difficulty in dealing with such deflated surface sites in a study of this kind, is the inability of the investigator to determine the specific geomorphological history of the site area.

Another situation that affects the hydration rate of surface deposited obsidian is the effect of shade. If flakes are located near an object producing shade, such as sagebrush, juniper trees, or boulders, they may be protected from direct exposure to the sun for some, if not all, of the time. These protected flakes will hydrate appreciably slower than those cirectly exposed to the sun because the air temperature in the shade is one-half to onethird as great as the temperature of an obsidian flake in direct sunlight. Although the effect may be short-term in most cases, a large boulder or a slow growing juniper tree can produce shade for many years. Over a long period of time, a false chronological difference (as portrayed by different hydration thickness measurements) could be produced between shaded and nonshaded artifacts.

The orientation of an obsidian artifact to the sun, variation in artifact thickness, artifact shape and the presence of inclusions (microcrystallites and bubbles) in 
the obsidian may affect the amount of heat absorption and conduction within the artifact. A thick artifact will be warmer at its top surface than at the bottom. Many inclusions in the obsidian may interfere with the heat conduction between the upper and lower surfaces. These two factors, in addition to the orientation with respect to the sun $(e . g .$, the amount of surface area exposed to direct sunlight), may produce variations in thickness of the hydration rind covering the surface of the artifact. Such results could appear to the observer to be the result of artifact reuse or wind abrasion.

The variation of hydration rind measurements, due to exposure to different temperatures, is nearly impossible to estimate and control. As discussed above, there are a number of factors that can change the ambient temperature to which any one artifact is exposed. Intrasite variations in geomorphological processes, shading and the orientation of an artifact with respect to the sun, are three factors that directly affect this ambient temperature. The only recourse is to minimize the hydration rind measurement variation produced by the first two factors. The method chosen for this task was the use of a sampling design based on random sampling. With a random selection of the sampling units, each unit within the site has an equal chance of selection. Anomalous hydration rind measurements, produced by differential temperature affecting artifacts in different 
areas within the site, will be minimized when this sampling procedure is utilized. If a nonrandom collection method were used, it would be possible for obsidian samples with anomalous measurements to be represented in the sample collection in a much larger proportion than they occur in the population. A random sampling method insures that these proportions will closely resemble those of the population. The third factor can be detected when the hydration rinds are measured. If differential hydration has occurred, the hydration rind will exhibit two or more thicknesses, a similar situation produced by artifact reuse. This phenomenon is distinguished from artifact reuse because rind width variability at each surface should be moderately large. One method of determining whether or not this is a factor introducing unwanted variation, is to thin-section the artifact at several locations along its long axis and take measurements at each. This method would constitute an enormous task if performed on each artifact. An alternative measure of this possible phenomenon is to record the hydration rind thickness at each different surface along the transverse axis (the number of surfaces varies with the conformation of the artifact) of the obsidian artifact. 


\section{CHAPTER III}

\section{PROCEDURES}

\section{Site Selection}

Site Selection Criteria and Discussion. Site selection was the first decision to make when this study was initiated. Three criteria had to be met in order to satisfy the needs of this project. First, each site to be sampled had to contain a large proportion of obsidian in its lithic waste. Such a condition implied that a nearby source of obsidian was readily available (and one which could provide an obsidian sample of relative chemical homogeneity for hydration analysis). Second, the lithic waste present at each site must be in fairly dense concentrations. The sampling design employed in this study requires that this criterion be met because a reasonable number of appropriate obsidian samples must be obtained from every collection unit. If a very sparse concentration of flakes was to be sampled using this sampling method, collection units might be positioned where no obsidian was present for collection. Third, even though the presence of a local obsidian source is implied by a large proportion of obsidian in a site's lithic waste, it was essential that each site be located near an aboriginally known obsidian source. 
The geomorphological environment is an important consideration when selecting a site for obsidian hydration analysis studies. It is a system of processes that alters the landscape and affects the position of artifacts in archeological sites. It is not known which type of environment produces the smallest disturbance on the contents of an archeological site, but thought and planning were required to determine the optimum situation for sampling. First, it was decided that two areas, in different geomorphological environments, should be sampled. The two sites that were selected differed widely in the geomorphological processes affecting them. One site was in a highland zone on a ridge top, far removed from the effects of channel erosion, dune formation and alluvial deposition. It was postulated that a ridge top location would provide the most stable geological environment, where the only processes altering the landscape were wind erosion, chemical weathering and sheet wash. The second site, on the other hand, was located nearby on the valley floor at the margin of a lake. Geomorphological processes such as channel erosion, dune formation, wind erosion, alluvial deposition, sheet wash, and lacustrian deposition are all, at one time or another, actively occurring in the vicinity of this site. These processes bury, re-expose and reposition artifacts at a rapid rate and can affect limited portions of the site, leaving the rest unaltered. The constant movement of arti- 
facts can introduce a large amount of variability into a sample of hydration measurements that is not reflective of the age differences of the artifacts being measured (as discussed above).

\section{Site Descriptions}

View Point site (MNWR 121). Originally surveyed in

1974 (Newman 1974), View Point chipping station (MNWR 121) is a small lithic scatter on top of a ridge, approximately five miles west of Harney Lake on the Malheur National Wildlife Refuge (Fig. 3). The ridge separates two small valleys to the north and south. The site area is fairly small (20 meters $\mathrm{N}-\mathrm{S}, 30$ meters $\mathrm{E}-\mathrm{W}$ ) and surrounds a small rock outcrop (Fig. 4). From the site area, both of the valleys are visible and game movements are easily monitored. Vegetation in the vicinity is sparse, supported by a very thin (5-10 cm.), rocky soil. The predominant geomorphological processes operating in the site area are wind erosion, frost wedging, sheet wash aná, to a lesser extent, chemical weathering. Soil formation and accumulation is quite slow in this locality and it is reasonable to assume that artifacts deposited here in the past have been on or near the surface until the present. One possible source for the obsidian found at this site is seven miles to the west on Bureau of Land Management (BLM) property. It is a large concentration of "float" obsidian in cobble form. This area was surveyed for the BLM during the 1977 Malheur 


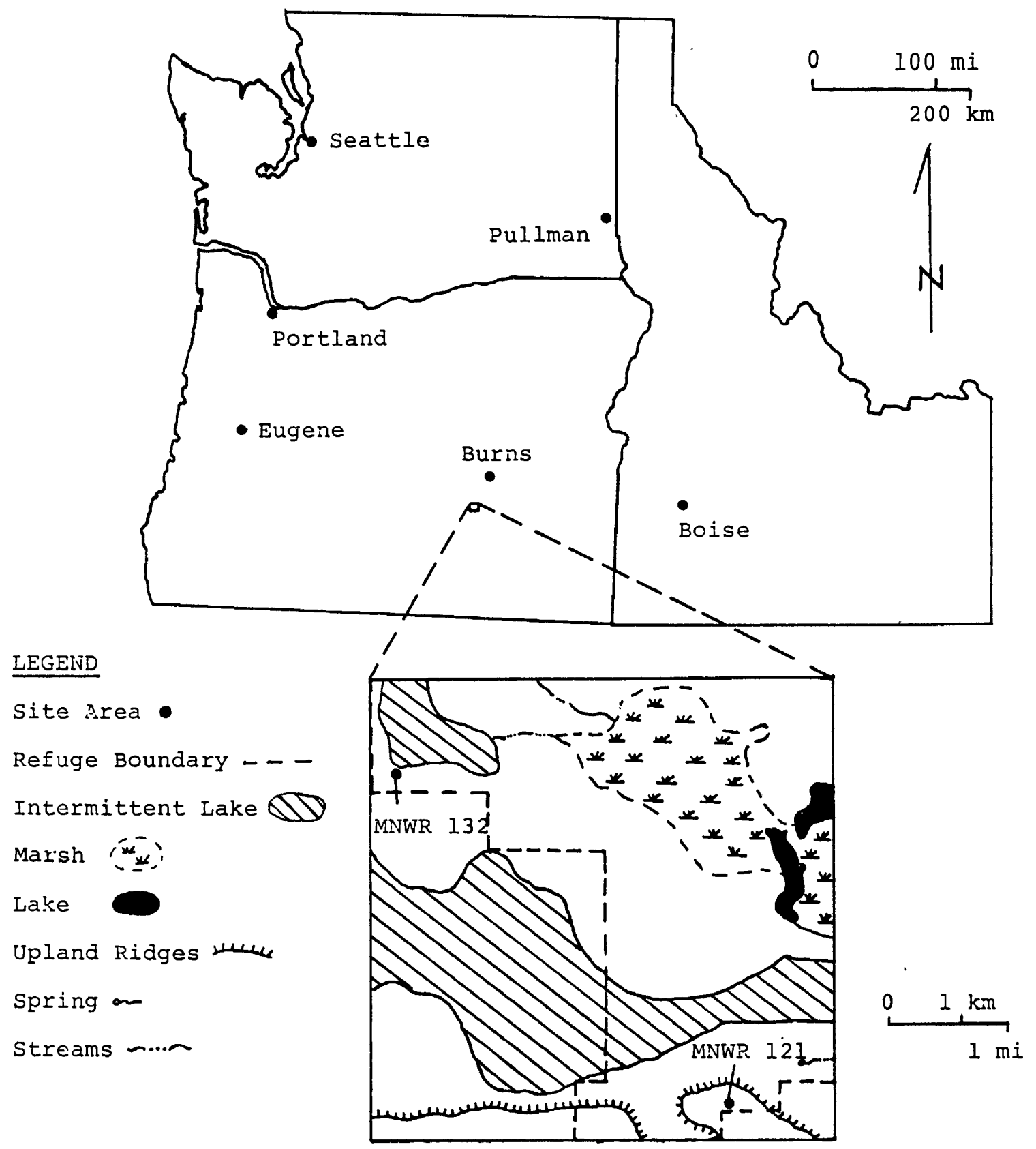

Figure 3. Area Map for Archeological Sites 


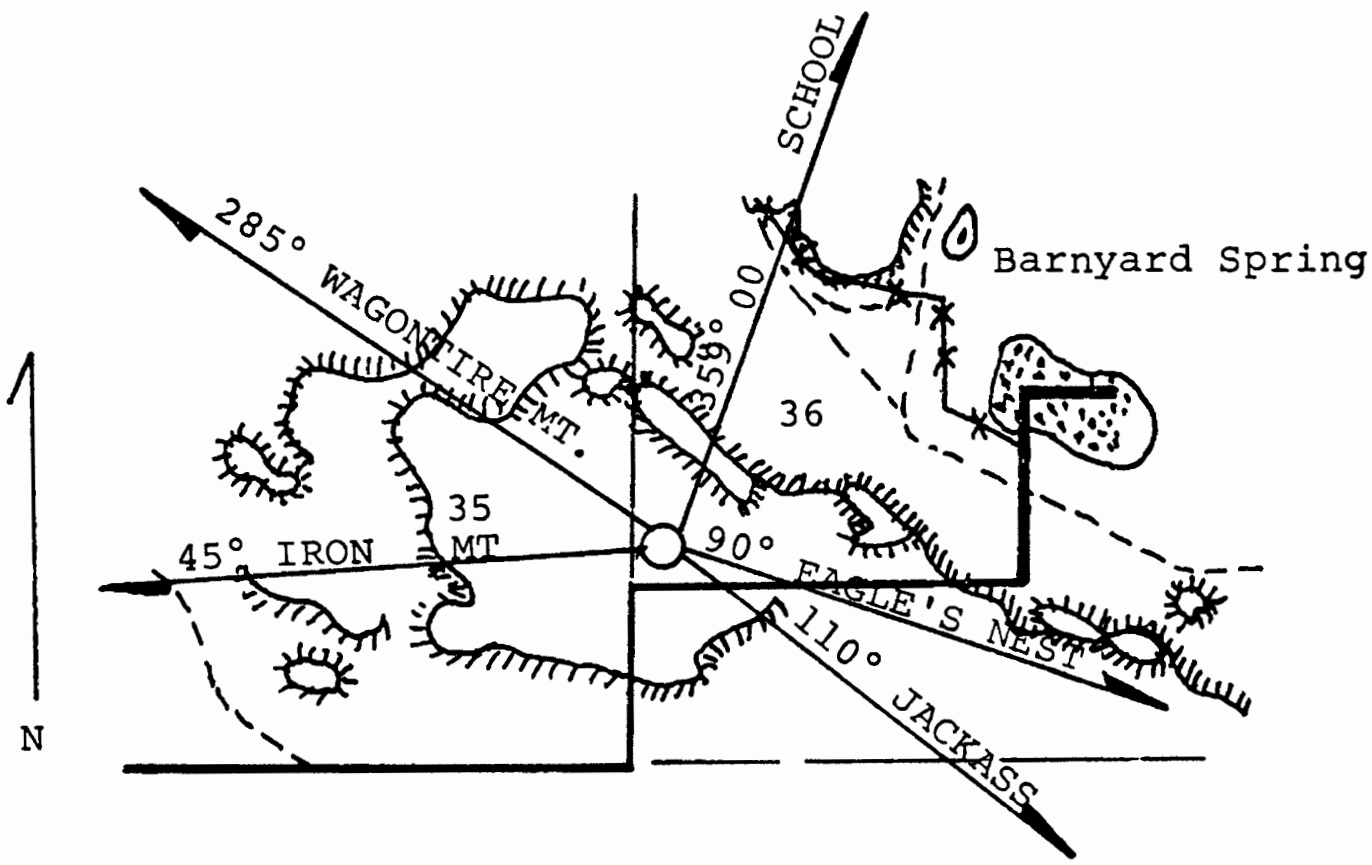

LEGEND

$\bigcirc$ Site Area

- Refuge Boundary

Scale in Miles

- Section Boundary

--- Light Duty Road

* * Fence

Dry Lake

Rimrock

Figure 4. Site Area Map: View Point Site MNWR 121 
National Wildlife Refuge (MNWR) Archeology Field School and has an associated quarry and flaking site near the cobble source. The cobbles have been eroded out of an extensive volcanic tuff (the Danforth Formation) that outcrops in the vicinity and in numerous other locations throughout the Harney and Malheur Basins. Other sources nearby may exist, but have not been located at this time. The lithic material deposited in the site area is not particularly abundant nor concentrated. This situation forced an alteration of the sampling plan in the field, as will be discussed below. Utilized flakes and blades comprised the majority of the artifacts noted at the site, although small numbers of prepared scrapers and projectile points were reported and collected during the 1974 field school. View Point chipping station functioned as a small, temporary hunting camp. An excellent view of game movements to and from the Harney Basin was available from this vantage point, the predominant artifacts (utilized blades and flakes) indicate butchering was a major activity and the rock outcrop provided shelter from prevailing winds commonly felt at such exposed locations.

Stinking Lake Site (MNWR 132). Stinking Lake habita-. tion site (Newman 1974) is located in southeastern Oregon, approximately ten miles west-northwest of Harney Lake on the Malheur National Wildlife Refuge (see Fig. 3). This large site is positioned along the southwestern margin 
of Stinking Lake and three-fourths of a mile along the western edge of a low rimrock that abuts the lake on its southern edge. Gradually sloping westward for one-quarter of a mile, the site lies in an area of considerable geomorphological activity (Fig. 5). Along its western edge, the site is subject to water erosion and there are many areas where "hard pan" surrounds sparse patches of vegetation. The soil at this point is very thin $(5-10 \mathrm{~cm}$.$) and the art-$ ifact scatters are densely concentrated in "blow-outs." To the east the soil is thicker $(15-30 \mathrm{~cm}$ ) and supports a more dense growth of vegetation. Artifact clusters are less visible in this area, but are still concentrated in blow-outs (deflated areas). Further east, directly against the low rimrock, there is active dune formation, where the soil is more than a meter deep and encroaching upon vegetation growth. Artifacts are seldom seen in this area, except along the margins of the dunes. A large amount of lithic material was observed at this site. Composed of seventy-five percent obsidian and twenty-five percent glassy basalt and chert, the lithic scatters were concentrated (40 pieces $/ \mathrm{m}^{2}$ ) and located primarily in deflated areas. With such a large amount of obsidian present in the site area, it was tentatively assumed that the obsidian was derived from a nearby source. One possible source for the obsidian found at this site is the same source cited above, three miles to the southwest. The artifact variety ob- 


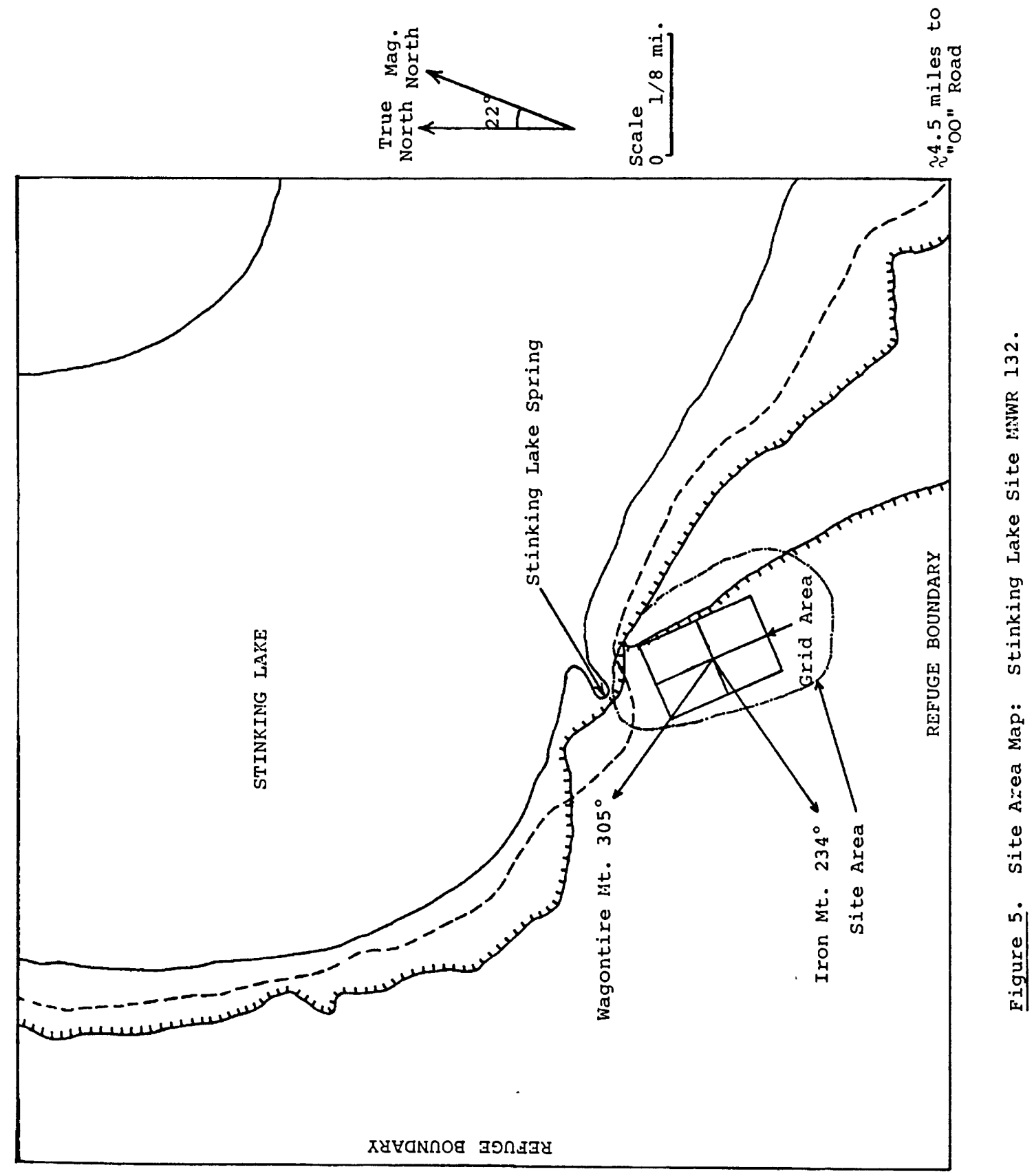


served at MNWR 132 suggests that it was a focus of many different activities in the past. Iumerous projectile points have been observed and collected by field school students, working with Dr. Thomas Newman. These projectile points exhibit considerable size and style variation, as will be discussed below. In addition to the projectile points, a number of knives, prepared scrapers, utilized flakes and blades, cores, manos, metates and a large mortar fragment of vesicular basalt were observed. The stinking Lake site probably functioned as a semi-permanent habitation site. The artifacts suggest a wide variety of subsistence activities were performed at the site such as: plant food preparation, butchering, artifact manufacture, and possibly hide preparation and mat and basketry manufacture. Other evidence, supporting the postulated semipermanent occupation of this site, is the seasonal abundance of waterfowl and marshland vegetation at stinking Lake and other nearby lakes, the seasonal migration of big game animals into the area and a perennial fresh water spring.

Sample selection

Sampling Design. A sampling design must be appropriate to both the needs of the particular study and to the conditions of the archeological site (the density of artifacts, nature of the terrain, and the size of the site itself). The needs of this study required that the sampling 
design provide: 1) a representative sample of obsidian flakes from all of the periods of site occupation, 2) the means of minimizing the effects of intra-site geomorphological variations that cause unwanted hydration thickness variation between obsidian flakes manufactured during the same time period, 3) a sample of obsidian flakes numbering at least 100 (from each site) from which 50 could be analyzed, and 4) the flexibility needed to adapt this design to sites of widely different size. The first requirement is achieved when the sampling design places collection units throughout the site area and maximizes the ability to sample a majority of the activity areas present at the site. The second requirement is fulfilled when a random element is incorporated into the sampling design. As Thomas (1976:251) aptly states "a basic rule in designing experiments is to control what can be controlled and to randomize the uncontrollable." As stated above, the amount of hydration thickness variation, due to intrasite geomorphological variations (differential temperature regimes) and the effects of shading, is virtually impossible to correct for. Therefore, collection units of a predetermined size should be randomly located throughout the site area to limit the number of hydration measurements in the sample with this unwanted variation component to a level that is proportional to the number present in the population. In order to satisfy the third requirement, as well 
as attain a representative sample, the collection units must be fairly small (if artifact density is moderately great) and there must be a large number of them. As a result, a small number of flakes is collected at each of a large number of collection units. The fourth requirement is fulfilled if the site is divided into a series of progressively smaller grid sizes, each contained within the next larger size. This allows the site to be subdivided into large units with an arbitrary number of these randomly chosen, and so on, down to the level of the collection unit. This feature of a sampling design imparts the flexibility that can be adapted to large or small sites. In summary, the sampling design required for this project must have many, widely spaced, randomly selected collection units of small size and the flexibility to be adapted to sites of all sizes.

A sampling design that fulfills these requirements is called the nested cluster sampling design. Quoting from Hester, Heizer and Graham (1975:292):

...Cluster sampling is a procedure by which more than one individual in the population being sampled is taken at each randomized position. In terms of a gridded archeological site, a number of randomized grid units are chosen and every item within that unit is collected. This procedure yields clusters of various kinds of cultural debris, in which spacing between major positions is random, but the spacing within the clusters is not random. This type of sampling is often used initially in collecting and excavating material to be subjected to other sampling techniques in the field and in the laboratory.

A nested cluster sample is a cluster sample extended to more 
than two levels (i.e., there is a hierarchical arrangement of grid sizes from large to small with a random selection of a predetermined number of sampling units at each level until, ultimately, the clusters of artifacts are collected). The implementation of this sampling design as well as the number and size of collection units will be described below for each of the two sites.

Stinking lake Site. Stinking Lake site, the larger of the two sites studied, has a surface area of over 15,000 square meters. Only 15,000 square meters were delineated as the collection area because the amount of lithic debris diminishes markedly outside of this zone. As one can envision, to reduce $15,000 \mathrm{~m}^{2}$ to the size of a small collection unit requires that the site be divided into several different size grids (Fig. 6). There were twenty-four 625 $\mathrm{m}^{2}$ sections encompassed by the collection area, of which twenty were randomly selected to ultimately contain each of the twenty one-meter square collection units. To attain sufficient site coverage, twenty of these twenty-four primary units were chosen to contain the collections units. A one-meter square collection unit was considered appropriate for this site because the artifact density was moderate to high and all twenty collection units should contribute to the total collection size of approximately 100 flakes. Reasonably good site coverage was accomplished with this first division. Each $625 \mathrm{~m}^{2}$ section was divided into 


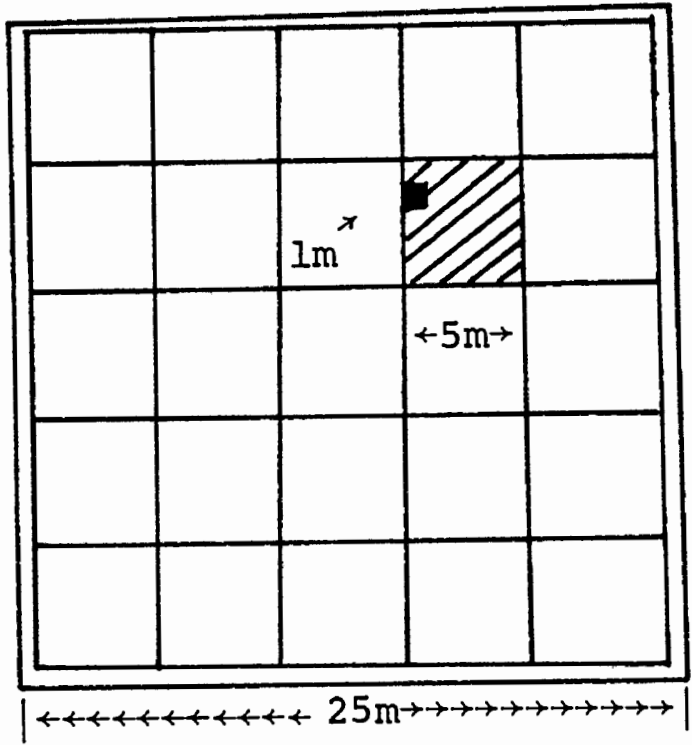

Primary Unit $\left(625 \mathrm{~m}^{2}\right)$

\#20

Secondary Unit $\left(25 \mathrm{~m}^{2}\right)$

\#7

Collection Unit $\left(\mathrm{Im}^{2}\right)$

$\# 10$

Figure 6. Example of one large grid section (\#20) from Stinking Lake site MNWR 132 to illustrate sampling design. 
twenty-five $25 \mathrm{~m}^{2}$ sections, of which one was to be randomly chosen in each to contain one one-meter square collection unit. Next, each $25 \mathrm{~m}^{2}$ grid section was divided into twenty-five one-meter square collection units and one from each $25 \mathrm{~m}^{2}$ was randomly selected. At this point, all of the appropriate obsidian artifacts within the one-meter square collection unit were collected and each was marked on its upper surface with white enamel for future reference in the lab. There, 50 of the total sample (131) were chosen at random before the hydration analysis was begun. This was accomplished by numbering every artifact in the collection and then generating 50 random numbers, representing the 50 samples for analysis. This final randomizing procedure was performed to eliminate any personal bias that might be introduced if the samples were hand picked from the collection. Each collection unit was located in the field with the use of pace and compass, after establishing the grid center. Possible Bias of the stinking Lake sample. It was brought to my attention (Kelly 1979) that any one or more of the sampling units may contain obsidian flakes derived, primarily, from one core. This possibility may bias the sample by not yielding a representative sample of all of the site's occupations. A visual inspection of the hydration measurements for a number of collection units will indicate the presence of this bias in the sample of obsidian flakes. Table II is a listing of all of the hydration 


\section{TABLE II}

TABULAR DISPLAY OF FIVE COLLECTION GRIDS AND THEIR HYDRATION VALUES FROM STINKING LAKE SITE

(MNWR 132)

Collection Grid Numbers

\begin{tabular}{lllll}
\hline $2-2-9$ & $19-13-23$ & $20-7-10$ & $9-1-18$ & $21-7-25$ \\
\hline 3.89 & $5.49 *$ & 4.11 & 7.45 & $6.59 *$ \\
4.31 & $5.35 *$ & 4.32 & 9.90 & $6.50 *$ \\
$5.08 *$ & 2.14 & $6.09 *$ & 6.42 & 4.51 \\
$5.18 *$ & 3.09 & $6.04 *$ & 6.03 & 5.93 \\
7.13 & $5.17 *$ & $6.20 *$ & & \\
4.74 & 3.24 & 5.80 & & \\
7.50 & 4.70 & 4.50 & & \\
\hline
\end{tabular}

* Denotes hydration measurements that are considered the same. 
measurements for five collection units from MNWR 132. In at least four out of the five there are two or more hydration thickness measurements that can be considered virtually identical when their standard deviations are taken into account. It is considered likely that most of these identical measurements were taken from obsidian flakes from the same core or produced from different cores at the same time. However, in each collection unit listed in Table II there are other hydration measurements that are widely different from these identical ones, indicating that other periods of site occupation are represented in the collection units as well. It is reasonable to conclude that although there may be some bias in the sample resulting from flakes struck from one core, each collection unit contains representatives of other periods of site occupation.

View Point site. A sampling design, similar to the one described for stinking lake site, was designed and applied to the MNWR 121 site report before the site was visited in the field. Upon arrival at the site area, very little lithic material was observed and at such low density that one-meter square sampling units, placed randomly over the site, were considered to be very impractical. No other random sampling technique was considered to be any more practical and a compromise was necessary. The site was divided into four quadrants (NE, NW, SE, SW). Each quadrant was sampled separately and all appropriate artifacts 
(glassy basalt, chert and extremely small obsidian flakes were not appropriate) were collected. This type of sampling plan is admittedly nonrandom, but to compensate for the bias introduced by this collection method, the hydration analysis sample was randomly chosen from the collected sample in the lab. As before, each artifact was numbered and 50 random numbers were generated. The hydration analysis sample was selected by matching numbered artifacts to the random numbers. This random selection process, used in the lab, should have minimized any unforeseen hydration rind variation, introduced by the field selection process.

Projectile Points

Their Function in This Study. When this study was first contemplated and designed, the intention was to deal solely with obsidian flakes, an abundant form of lithic debris at most archeological sites in southeast oregon. After some thought and research however, the possibility of including a small sample of diagnostic artifacts in the hydration analysis was proposed. Projectile points were included to provide positive or negative evidence for interpreting the relative chronology produced by the hydration analysis of the flakes. First, it is apparent that sites have been occupied more than once in the past, if many widely different types of projectile points are reported and observed as a part of their assemblage. Second, if a sample of different types of projectile points from each 
site is analyzed, the resultant chronological ordering may support the one produced by the flake hydration data. To accomplish this, several artifact classifications and chronologies were consulted, each artifact was classified and their hydration ordering was compared to ones provided by the publications. If the two chronological orderings tend to agree, the flake hydration data are considered to be reasonably accurate and illustrative of the sites' histories. If the two orderings do not agree there are factors obscuring the proper ordering that must be explained. Method of Selection. The projectile points were selected from the cataloged collections housed at portland State University in the Anthropology Department. No provenience data was provided other than the site location where the projectile points were collected. Several different projectile points, indicative of widely separated time periods, were selected from the total collection for hydration analysis.

Classification. Three published artifact classifications/chronologies were consulted to provide a basis for the typological ordering of the projectile points in this study (Appendix A). 


\section{LAB PROCEDURES}

\section{Preparing the Thin sections}

Initially the obsidian artifacts are washed with a small brush and warm water. Next, they are cut, perpendicular to their long axis, into two pieces. The cut is made so that it is at a right angle to the flake surface in order to attain the highest degree of accuracy in measuring the width of the hydration rind. This cut is accomplished with the use of a continuous-rim diamond cut-off saw blade, mounted on a standard, water cooled rock saw. One of the pieces from each pair is then lapped in a figure-eight pattern on a $3 / 8$ inch glass plate with a slurry of silicon carbide (size 400) grit and water. This initial lapping is done to remove saw marks and any chippage on the edges, produced in the cutting process. The obsidian piece is again lapped on a glass plate with a slurry of silicon carbide (600 grit) and water to remove the lap marks produced by the 400 grit and to further smooth the obsidian piece. The ground surface is then washed with detergent, and thoroughly rinsed and dried. Each sample is then mounted, polished surface down, to a frosted glass petrographic slide with Petropoxy 154 at 154 degrees $C$. for 8 minutes. After curing, the mounted samples are allowed to cool at room temperature. Then the mounted samples are 
sectioned on a thin-section machine, parallel to the first cut, to remove all but approximately $1 / 16$ of an inch. The mounted sections are lapped briefly with a slurry of silicon carbide powder (400 grit) and water, to remove any chippage and saw marks produced in the cutting process. The final lapping is accomplished, using a slurry of 600 grit, silicon carbide powder and water on a glass plate. Iapping is continued until the thin section is fairly transparent and the shadow, produced by the edge of the sample, is minimized. Repeated inspections under a microscope at low power will aid in achieving the appropriate thickness. Friedman and Smith (1960) suggest the final thickness should be between 0.002 and 0.003 inches. I found it extremely difficult to measure or estimate the final thickness and relied heavily on the transparency and shadow effect of the edge to insure that it was produced. The ground sections are then washed with detergent, rinsed and dried. After drying, a cover slip was applied to each sample with Petropoxy 154 and cured at 154 degrees $C$. for 10 minutes. After cooling at room temperature, excess epoxy is removed with a singleedged razor blade and the finished thin sections are washed with detergent and warn water.

Measuring The Hydration Rind Thickness

The equipment necessary to make these measurements is a compound microscope with three objectives $(40 x, 63 x, 100 x)$ and a $12.5 \mathrm{x}$ occular drum micrometer that is accurate to 0.2 
microns. Both of the instruments used in this study were manufactured by Zeiss.

Place the prepared thin section on the microscope stage and locate an edge of the obsidian artifact under the $40 \mathrm{x}$ magnification. Most hydration rinds are visible at this magnification, although some are only seen when the $63 x$ or $100 \times$ objective is in use. The hydration rind is parallel to the outer edge of the obsidian sample and is visible due to the presence of a dark line that is the boundary between the hydrated and nonhydrated obsidian glass. After the rind is located, it is necessary to determine if it has been bisected at the proper angle (i.e., perpendicular to the flake surface). If it has been cut at the proper angle, the outer edge of the obsidian and the dark line of the hydrated-nonhydrated interface will not change position when the sample is moved in and out of focus. If the two Iines change position when the focus is adjusted, the proper cut angle has not been achieved at that location. There is a good possibility that the proper angle can be viewed somewhere else along the perimeter of the sample and these are the locations where the rind width is measured. As a result, it is normally necessary to survey the entire artifact perimeter before a satisfactory number of measurements are attained. An occasional sample may have no appropriate locations for measurement and must be re-cut and another thin section prepared. Once the appropriate portion of the 
hydration rind is located its width can be measured. The drum occular micrometer is used for this purpose. It has a scale in units and a vernier arranged in a circle around the periphery of the field of view. Bisecting the field of view are two dashed, parallel lines, one fixed and one moveable. The moveable dashed line can be moved away from or toward the fixed line by rotating the large screw on the side of the micrometer. Both lines can be rotated around the field of view to accommodate the angle of the hydration rind. Two small set screws are positioned on the side of the micrometer to move the fixed line up and down in the field of view to enable the observer to position the fixed line directly over either the outer edge of the artifact or the interior hydration rind boundary. Once the fixed line has been placed directly over either of these two boundaries, the moveable line is positioned over the opposite boundary. The micrometer "units" scale and vernier (in the field of view) are then read and this number is recorded. The moveable line is moved toward the fixed line until the two merge and form a solid line. The "units" scale and vernier are again read and the number recorded. The absolute value of the difference of the two readings is equal to the width (thickness) of the hydration rind in micrometer units. These units are converted to microns by multiplying them by a conversion factor. In this study, most of the measurements (unless otherwise noted) were taken at a magnification 
of $787.5(63 x * 12.5 x)$. At this magnification, one unit on the micrometer is equal to 16.47 microns (the conversion factor). To minimize measurement error, more than one reading was taken at each location. As there was a potential for rind width variability within an obsidian sample several measurements were taken on each surface of the obsidian samples to assess this variability.

Measurement Error

There are two inherent factors that influence the degree of accuracy attained when measuring hydration rinds. First, there is a small variation between measurements on one thin section that usuaily amounts to 0.01 units (equals $0.1647 \mu \mathrm{m})$. This appears to be a fairly large measurement error, but the occular micrometer is only accurate to 0.01 units. The other inherent factor is the conversion process from micrometer units to microns. As mentioned above, the micrometer is accurate to 0.01 units, but when the units are converted to microns, the measurement error is enlarged by a factor of 16.47. Measurement variation and the inaccuracy of the micrometer at units smaller than 0.01 units results in an average of $0.1647 \mu \mathrm{m}$ or greater error. Every measurement must be taken with extreme care to minimize this error and a large number of measurements from each thin section is preferred for the most accurate results. 
Preparation of Samples for Index of Refraction Measurements

A small piece (approximately the size of a dime) of obsidian from the nonhydrated portion of the sample is selected and washed to remove any dust and marking compound. It is important to label a small vial with the sample number to prevent mislabeling. Next, the sample is crushed in a porcelain mortar with a porcelain pestle. The obsidian sample is ground into a fine powder and then transferred to a sieve (60 mesh) and collected in a petri dish. The remnants in the sieve are then reground and transferred to the sieve. The powder in the petri dish is then placed in the labelled vial and stored for analysis. After each sample is prepared, all of the apparatus should be wiped clean to prevent cross contamination of obsidian samples. Measurement of the Index of Refraction. The method of determining the index of refraction of a selected sample was the Becke line method. A brief description of the Becke line is presented below.

A grain in oil, viewed with the microscope objective focused slightly above the position of sharpest focus, will usually display two thin lines (one dark and one bright) concentric with the border. The brighter of these is always closest to the material having the higher refractive index and, moreover moves toward the medium having the higher refractive index, if viewed as the microscope is racked steadily upward above focus. This line, which represents a concentration of light because of refraction or reflection, or both at the grain-oil boundaries is called simply the Becke line in most works... Becke lines become particularly obvious as the substage iris diaphragm is closed down...(Bloss 1961:50). 
...Becke lines are generally attributed to (1) refraction at the lenslike edge of the grain or (2) total reflection at the grain-oil boundaries, or both. Their explanation by refraction presumes that a grain whose index is greater than the oil's acts as a converging lens whereas a grain whose index is lower acts as a diverging lens. Consequently, the bright Becke line, observed as the microscope is racked upward from a sharp focus appears to move toward the grain or toward the oil, whichever has the higher index... (Bloss 1961:50).

If the index of refraction of the grain is close to the index of refraction of surrounding oil, the bright and dark Becke lines will be observed to possess distinctive colorations if white light is the illuminant (Bloss 1961:55).

The criteria for an exact match of the index of refraction of both oil and grain are (1) the approximate equality in intensity of the two Becke lines and (2) the color of these lines... The Becke line entering the oil should be slightly more intense than that entering the grain. For such a match, the Becke line entering the grain should be an orange-tinged yellow whereas that entering the oil should be a green-tinged blue (Bloss 1961:58).

Select a liquid of known refraction and place a drop on a clean glass slide. Transfer a small amount of glass powder from the labelled vial into the oil with a toothpick. Extreme care should be taken to insure that cross contamination between oils does not occur. Place the glass slide on the microscope stage under the $10 \mathrm{x}$ size objective and bring the grains into focus. It is important that the substage iris is closed so that the amount of light is reduced. The bright Becke line should be visible at the periphery of the grains. For the best results and the most ease in measurement, an obsidian fragment with few inclusions should be chosen. When focusing above the sharpest focus, the line 
will appear to move either into the grain or into the oil $(e . g .$, toward the material of higher refraction). If the bright Becke lines moves into the grain, an oil of higher refraction should be tested next. If the bright Becke line moves into the oil, an oil of lower refraction should be tested next. When the grain and oil are similar in their indices of refraction, the Becke lines will be colored. I found these colors useful in interpreting to which of the two indices the grain is closer. This situation occurs frequently because the oils are prepared in a series of indices that are 0.002 units apart. Most obsidian samples do not have exactly the same index of refraction as the oil they are immersed in. Interpretation of the colors helps determine approximately where the grain's index of refraction is located in the 0.002 unit range. The oil that produces the colors closest to the quoted combination is the index of refraction nearest to the grain's. After determining an obsidian sample's index of refraction, a clean set of slides should be prepared and the work area should be dusted and cleaned to avoid obsidian and/or oil contamination of the next determination. During all of the index of refraction measurements, the temperature of the oil was kept quite near 25 degrees $C$., eliminating the necessity to apply the oil temperature correction factor. 


\section{CHAPTER IV}

\section{RESULTS}

\section{Hydration Data}

Flakes. The hydration thickness data from Stinking Lake Site (MNWR 132) ranged from 2.14 to $9.90 \mu \mathrm{m}$, and had a standard deviation range of 0.069 to $0.413 \mu \mathrm{m}$. The 0.413 $\mu \mathrm{m}$ value is reported only for the sake of completeness, but was discarded with its hydration value when the data was plotted. Katsui and Kondo (1978:123) report that in their hydration analysis of obsidian artifacts from Hokkaido, Japan, the measurement standard deviation ranged from 0.03 to $0.26 \mu \mathrm{m}$ and averaged somewhere between 0.1 and $0.2 \mu \mathrm{m}$. My results tend to agree with these. Any standard deviation much greater than $0.2 \mu \mathrm{m}$ is indicative of hydration rind width variation within the artifact. A graphical display of the hydration thickness data (Fig. 7) illustrated the presence of several "clusters" of hydration values, separated by gaps. In addition, there are three hydration values repeated twice and one repeated three times. When the standard deviations are plotted with each hydration value (Fig. 8), the gaps tend to close and the distribution becomes more continuous. A majority of the hydration values range from approximately 4 to $6.5 \mu \mathrm{m}$, with most of the pro- 


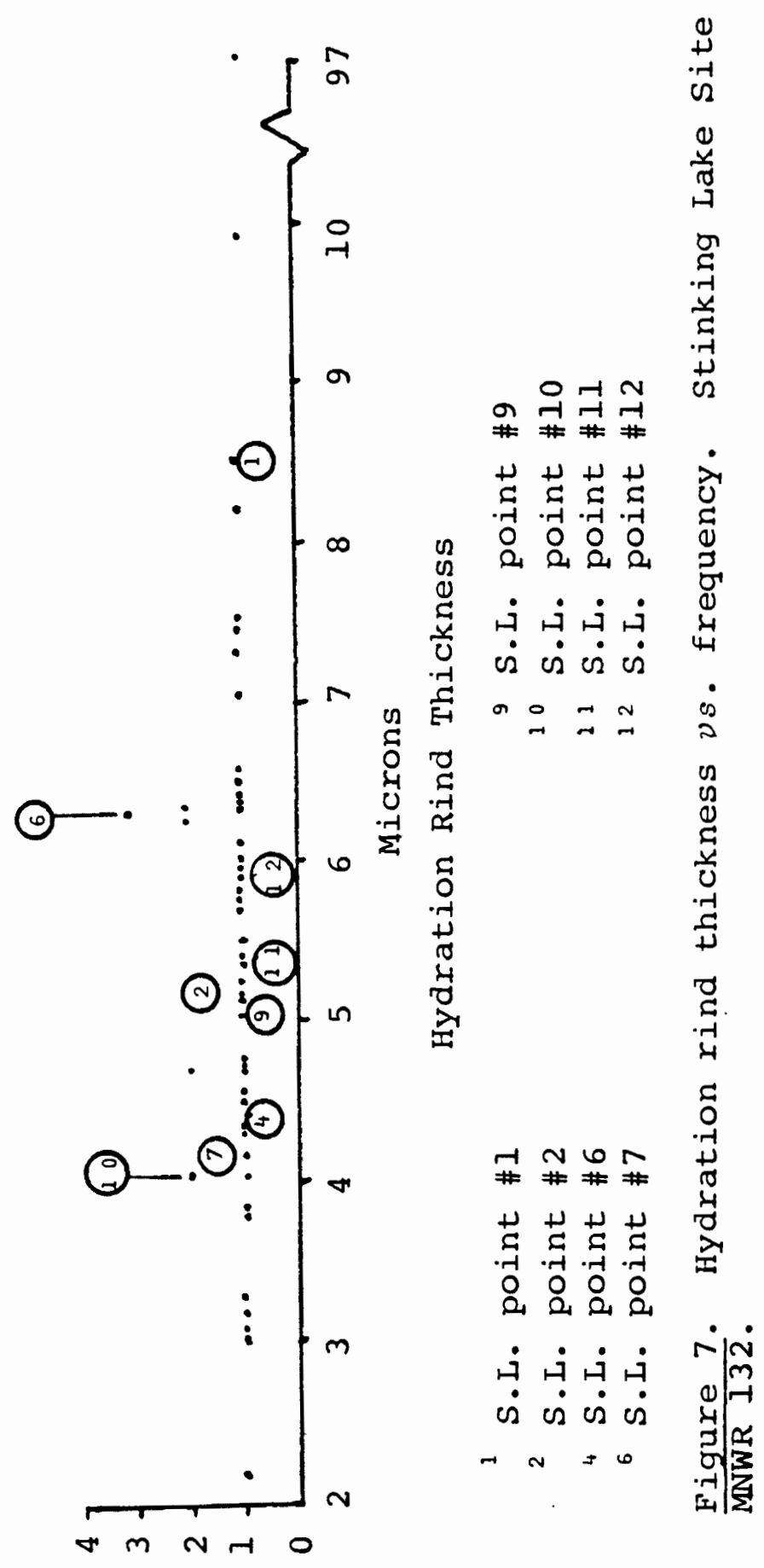

KоนаnБаx 


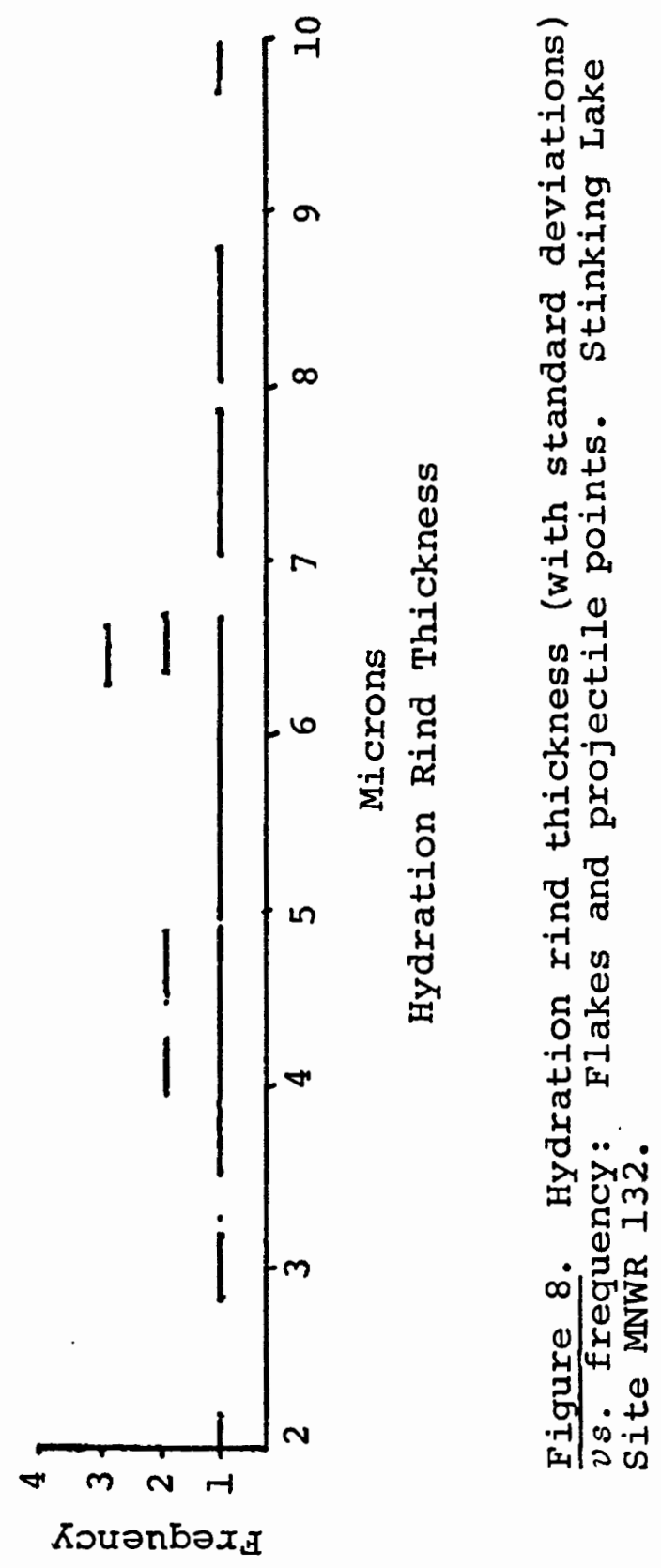


jectile point values included in this range.

The hydration data from View Point chipping station (MNWR 121) range from 4.24 to $6.7 \mu \mathrm{m}$, and had a standard deviation range of 0.08 to $0.59 \mu \mathrm{m}$. As with the MNWR 132 data, the hydration value that was associated with this high standard deviation was discarded when the data were plotted. The standard deviation values for MNWR 121, like those from MNWR 132, tend to agree with those reported by Katsui and Kondo (1978:123). A graphical display of the data (Fig. 9) shows relatively large and fewer clusters of hydration values than seen for MNWR 132. The data, especially between 5.0 and $6.5 \mu \mathrm{m}$, are almost continuous, with gaps of approximately $0.1 \mu \mathrm{m}$ in two locations. Within that same range, where a majority of the values occur, there are six values that are duplicated. When the standard deviations are plotted with their respective hydration values, the gaps close and the distribution looks more continuous (Fig. 10).

Some of the thin sections did not yield hydration measurements. Eight other samples yielded two different values (see Discussion).

Projectile Points From Stinking Lake Site (MNWR 132).

Stinking Lake site appears to have been occupied several times in the past, as reflected in the wide variety of projectile points present there. The variety of projectile points seen at the site and in collections from the site 


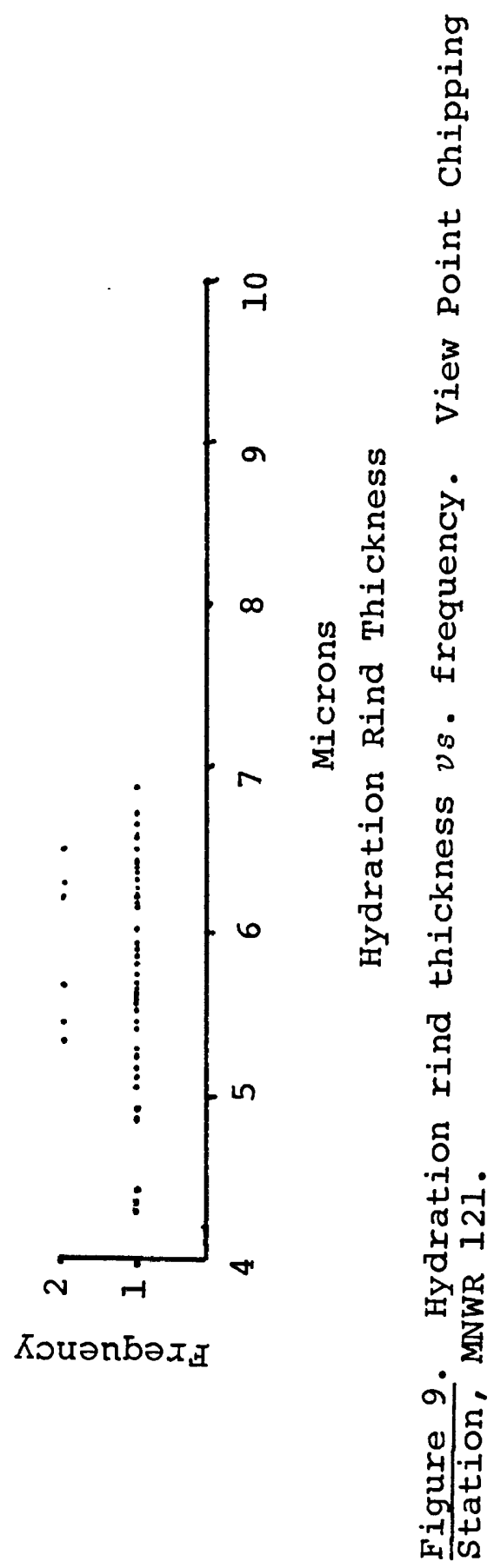




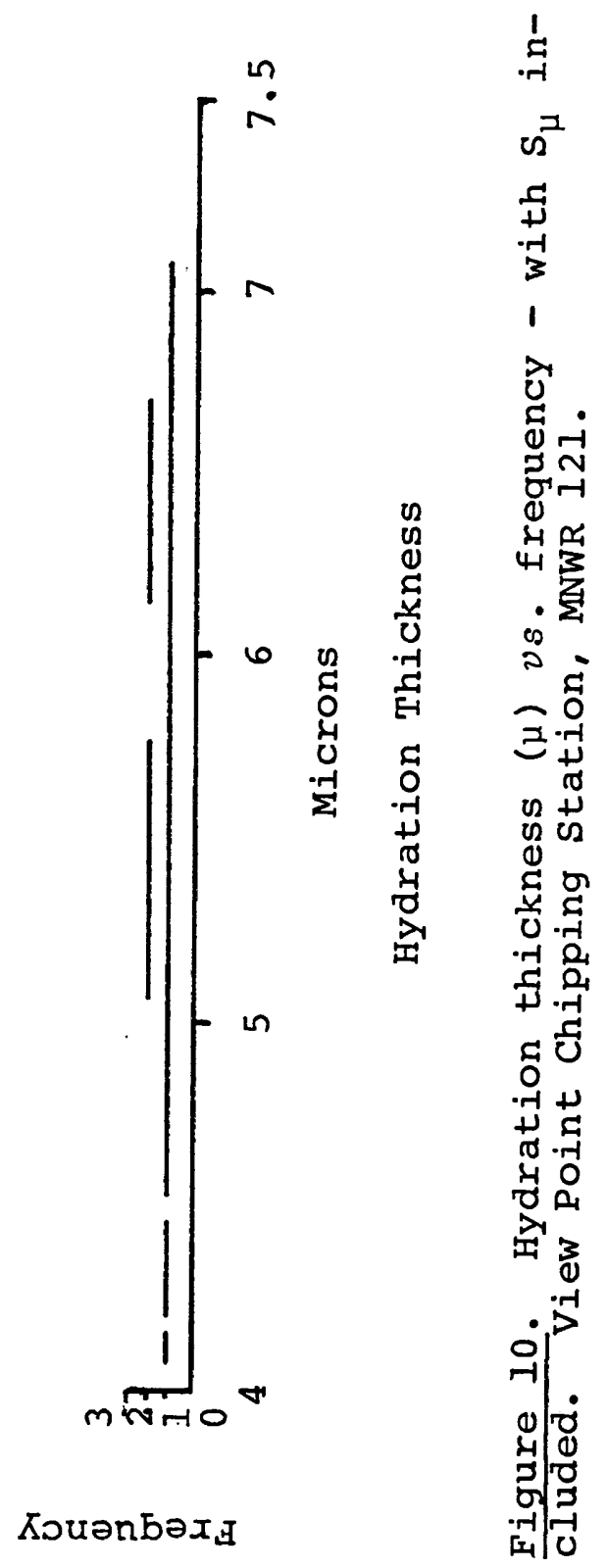


include: a fluted point, stemmed and/or lanceolate points, large corner-notched points, large side-notched points, transverse points, small corner-notched points and small stemmed points (Fig. 11).

The hydration measurements (Fig. 12) show a total range of over $4 \mu \mathrm{m}$, from 4.11 to $8.45 \mu \mathrm{m}$. Although this range cannot be translated into years, it can be assumed to represent a lengthy period of time, as illustrated by the variety of projectile points within that range. Included in the hydration analysis were: S.L.P. I $(8.45 \mu \mathrm{m})$, a fluted point; S.L.P. $6(6.48 \mu \mathrm{m})$, a large stemmed or lanceolate point; S.L.P. $12(5.90 \mu \mathrm{m})$, a Northern sidenotched point; S.I.P. II $(5.41 \mu \mathrm{m})$, a Great Basin Transverse point; S.L.P. $2(5.27 \mu \mathrm{m})$, an Elko eared point; S.L.P. 9 $(5.09 \mu \mathrm{m})$, a large side-notched point; S.L.P. $4(4.36 \mu \mathrm{m})$, a small corner-notched point; S.L.P. $7(4.22 \mu \mathrm{m})$, a large lanceolate or stemmed point and S.L.P. $10(4.11 \mu \mathrm{m})$, a Pinto square shoulder point. It is important to note that each of the projectile points, with the exception of S.L.P. I, has a hydration rind measurement that places it in one of the broad groups formed by the flake hydration data.

$$
\text { projectile points From View Point site (MNWR 121). }
$$

Only four projectile points are known from this archeological site, two of which are unsuitable for hydration analysis. One of the four points is too incomplete to classify, two are of the Elko eared type and one is classified as a Hum- 


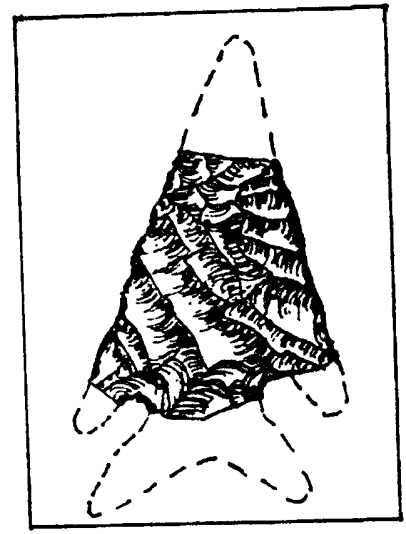

A

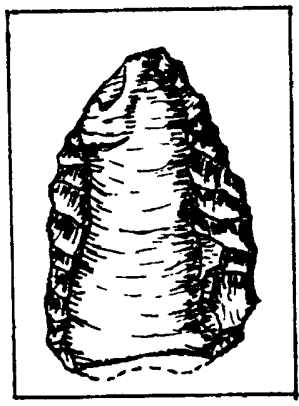

B

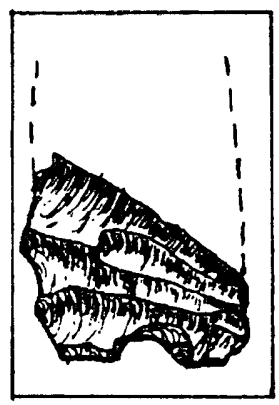

C

A) S.L.P. 2 - Elko eared, 5.27 microns.

B) S.L.P. 1 - Fluted point, 8.45 microns.

C) V.P. 62 - Humboldt Concave Base A. No rind observed.

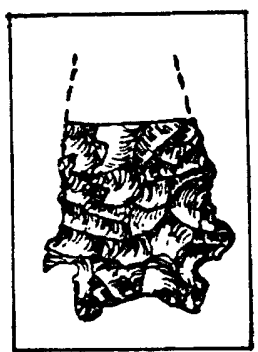

D

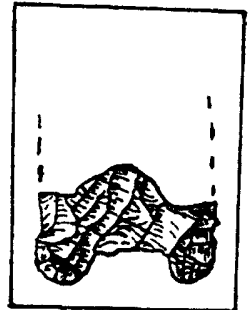

E

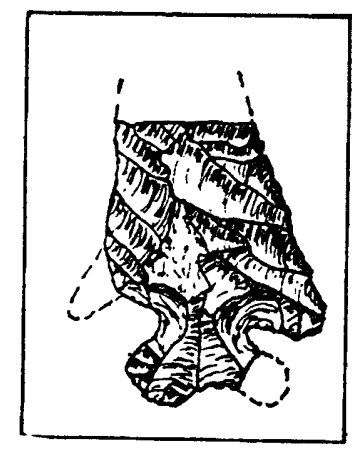

F

D) S.L.P. 4 - Type 2E (Fagan 1974), 4.36 microns.

E) S.L.P. 5 - Type 7C (Fagan 1974), no rind observed.

F) V.P.P. I - Elko eared, 6.26 and 8.84 microns (unreliable). 


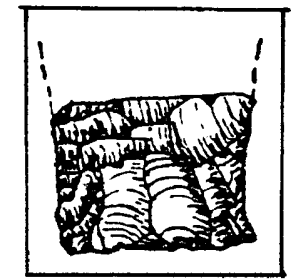

G

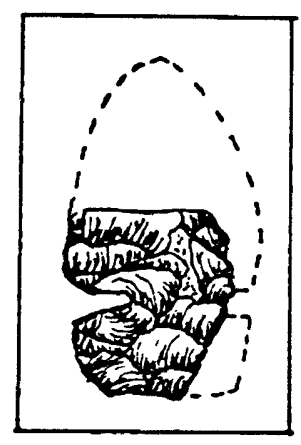

H

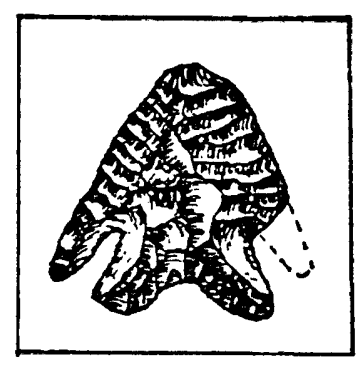

I

G) S.I.P. 6 - Type 3 or Haskett (Layton 1972), 6.48 microns.

H) S.L.P. 12 - Northern side-notched, 5.9 microns.

I) S.I.P. 10 - Pinto square shoulder, 4.11 microns.

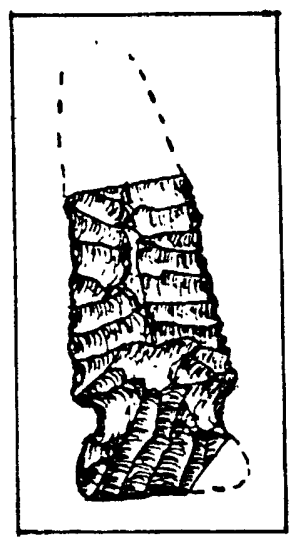

$\mathrm{J}$

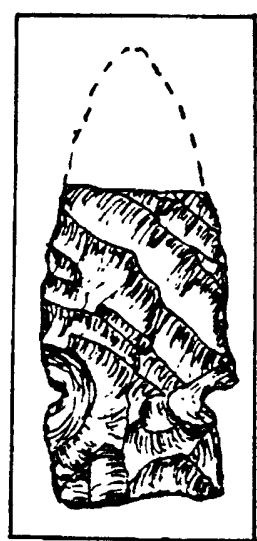

K

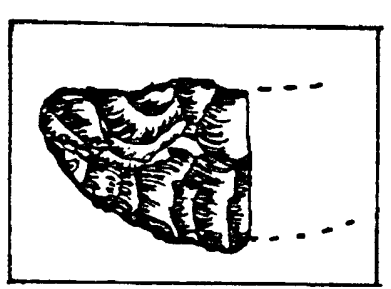

L

J) S.L.P. 9 - Type 9 (Layton 1972), 5.09 microns.

KL S.L.P. 8 - Northern side-notched, no rind observed.

L) S.I.P. 11 - Great Basin Transverse, 5.41 microns. 


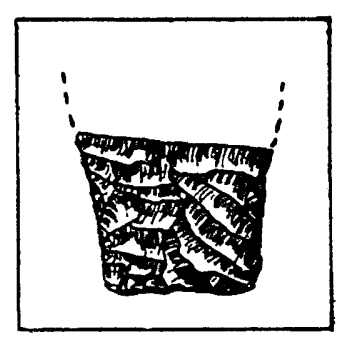

M

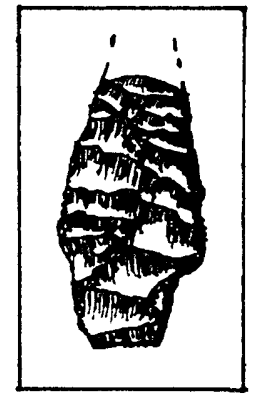

$\mathrm{N}$

M) S.I.P. 7 - Type 3 or Haskett Type (Iayton 1972), 4.22 microns.

N) S.I.P. 13 - Type 5A (Fagan 1974), not analyzed.

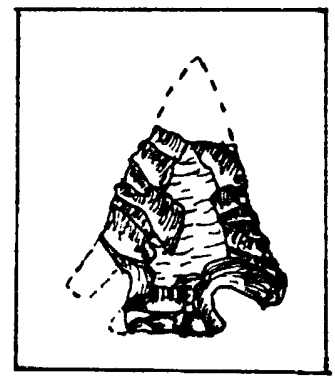

0

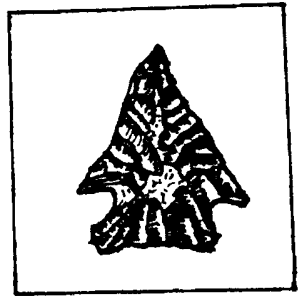

P

O) S.I.P. 14 - Rose Spring corner-notched, not analyzed.

P) S.L.P. 15 - Type 2F (Fagan 1974), not analyzed.

Figure 11 


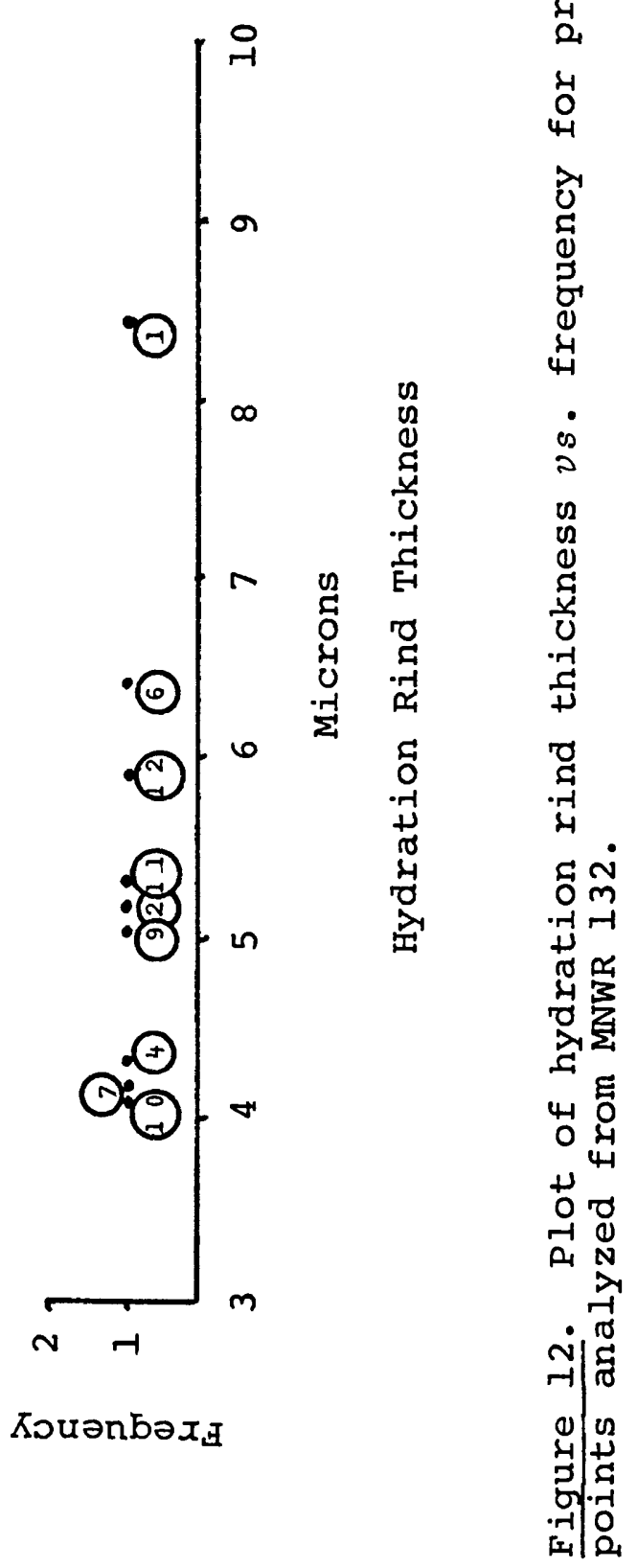


boldt Concave Base Type A. The Humboldt point and one of the Elko eared points were included in the hydration analysis. V.P. 62, the Humboldt point, produced no observable hydration thickness data and V.P.P. 1, the Elko eared point, produced two hydration thickness values $(6.26$ and $8.89 \mu \mathrm{m})$, neither of which are reliable as they were derived from only one measurement each.

Index of Refraction

Flakes and Projectile Points. Fourteen samples from both archeological sites were tested for their index of refraction, of which twelve were flakes or blades and two were projectile points. Taken as a whole, ten out of the fourteen (71.4\%) determinations were in the range of $1.494-1.496$, two of the fourteen (14.38) were in the range 1.492-1.494, one (7.18) was in the range $1.496-1.498$ and another (7.1\%) was determined to be quite near 1.490 .

The index of refraction measurements from View Point site exhibit a great degree of homogeneity (Fig. 13), with only one out of the total of seven measurements different from the rest.

Stinking Lake site obsidian samples display slightly less homogeneity than do the View Point site samples, with four of seven falling in the range 1.494-1.496 (Fig. 14). Two of the three measurements out of this range were derived from projectile points (S.L.P. 7 and S.L.P. 6).

To test the relationship between the index of refrac- 
m N $N$

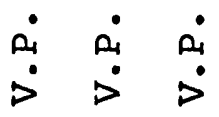

I I I

040

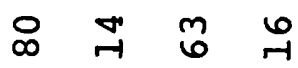

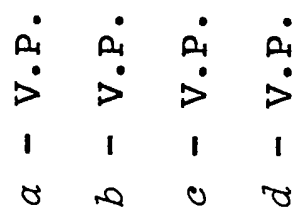

亗

畐

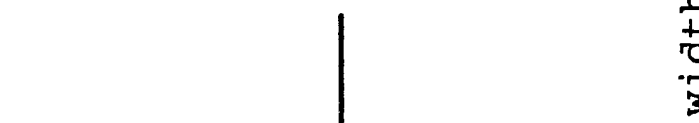

.7.7

.

$1-1$

14

吉

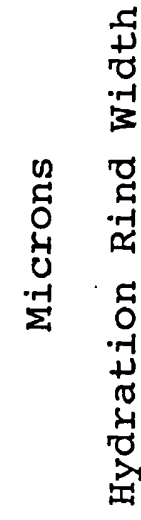

0 द

(1)

它

.

पु

पे مू.

क्त

تص 


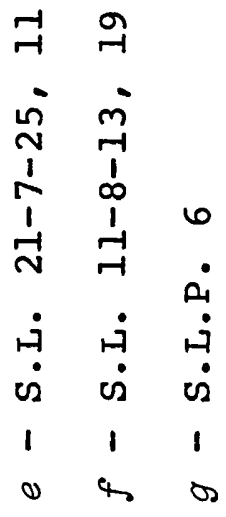
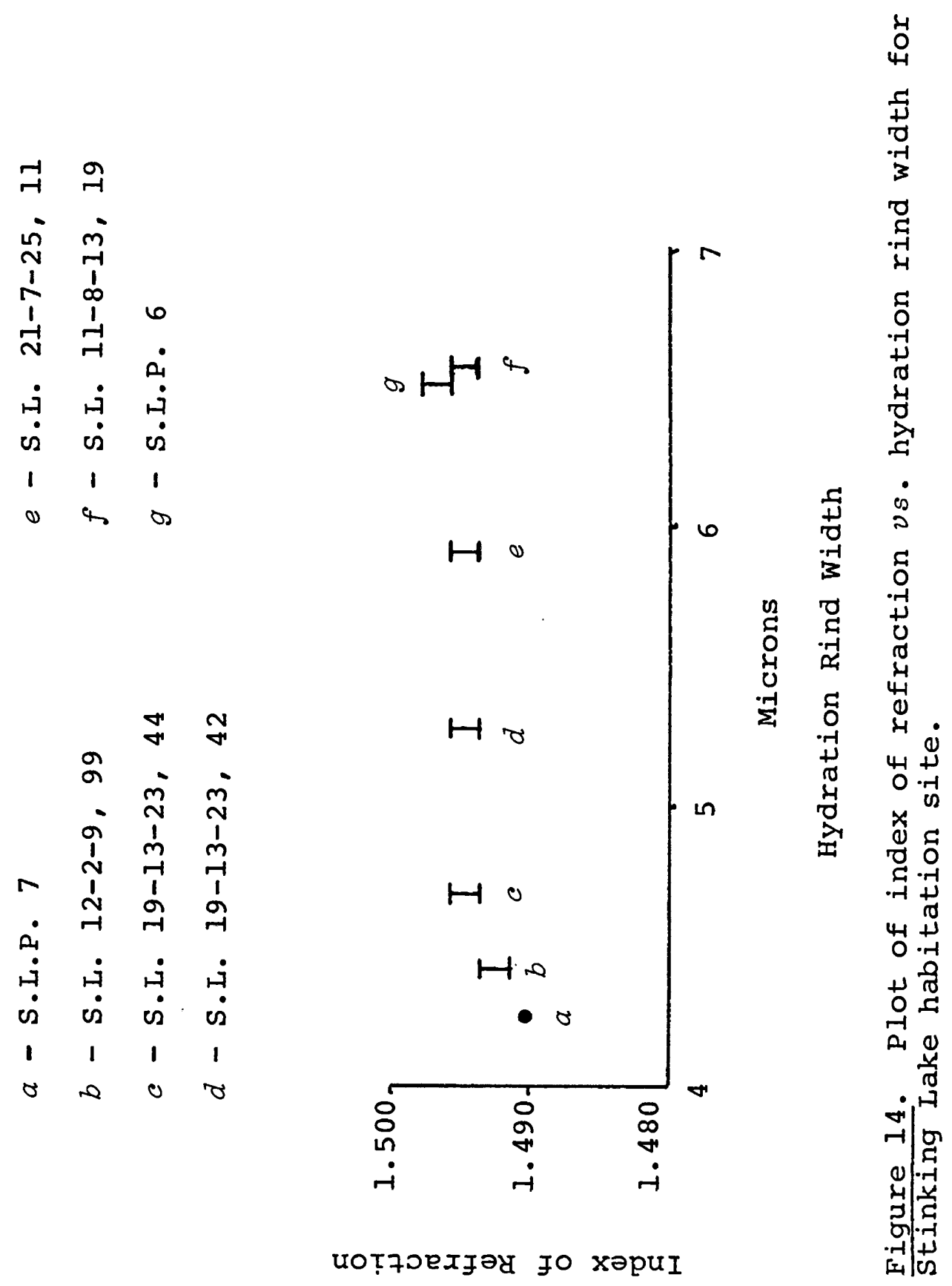
tion value and the chemical composition of a particular obsidian, four samples with known different trace element compositions were analyzed (Fig. 15). Of interest in this study was the possibility of two chemically different obsidians displaying the same index of refraction range. These samples were provided by Dr. Marvin Beeson (Portland State University, Earth Sciences Department) and have been analyzed for their chemical content by Instrumental Neutron Activation Analysis. Two samples (0-12 from Hines obsidian quarry and 0-53 from U.S. 395 near Wagontire, oregon) had the same index of refraction range, 1.492-1.494, while the other two had index of refraction ranges of $1.488-1.490$ and 1.496-1.498. As indicated, $0-12$ and $0-53$ are examples of the above mentioned possibility. Whether or not they have precisely the same index of refraction is unknown as the analysis results are accurate to a 0.002 unit range. As shown in Table III they do have compositional differences. The situation, where two chemically different obsidians have exactly the same index of refraction, can and does exist. Friedman and Long (1976) report two obsidian samples (from Big Obsidian Flow and Kerlingerfjoll) of different major element compositions that have the same index of refraction (see Table I, Part B). However, the two samples are very similar in their major element compositions as would be expected since their indices of refraction are the same. 


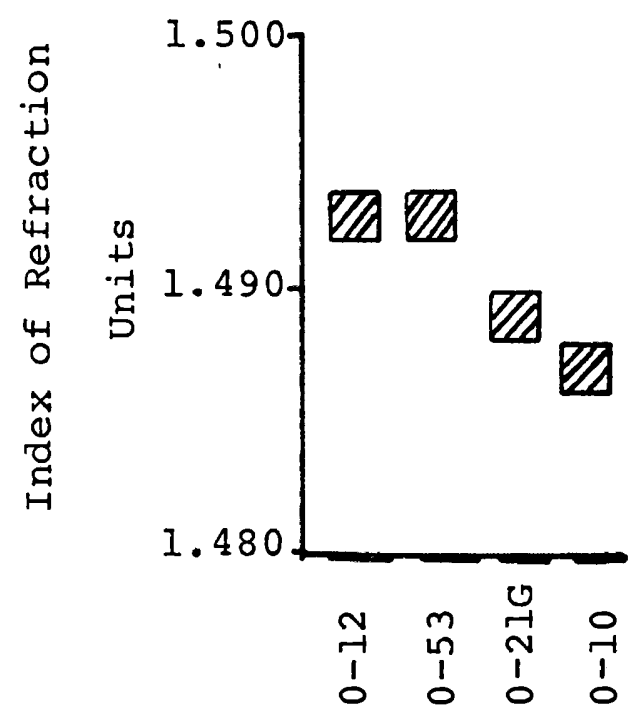

Sample Number*

*0-12, rhyolitic obsidian from west of Burns, Oregon near radar station

0-53, rhyolitic obsidian from U.S. Highway 395 near Wagontire, Oregon.

0-2lG, obsidian fraction from ash-flow tuff from U.S. Highway 395 north of Burns, Oregon.

0-10, rhyolitic obsidian from Glass Buttes, Oregon.

Figure 15. Plot of index of refraction for four samples donated by Marvin Beeson, Ph.D. 


\section{TABLE III}

COMPOSITIONAL PARAMETERS FOR SAMPLES 0-12 AND 0-53

(Abundances in ppm except where specified)

\begin{tabular}{|c|c|c|c|c|c|}
\hline \multirow[b]{2}{*}{$\mathrm{Na}(8)$} & \multicolumn{2}{|c|}{$0-12$} & \multicolumn{3}{|c|}{$0-53$} \\
\hline & $3.13 \pm$ & .06 & 3.68 & \pm & .08 \\
\hline $\mathrm{Cs}$ & $3.4 \pm$ & $\pm \quad .2$ & 4.4 & \pm & .3 \\
\hline La & 36.9 & \pm 1.7 & 33.6 & \pm & 1.6 \\
\hline $\mathrm{Ce}$ & 63 & \pm 4 & 68 & \pm & 4 \\
\hline $\mathrm{Sm}$ & $7.04 \pm$ & \pm .16 & 8.98 & \pm & .19 \\
\hline $\mathrm{Eu}$ & $0.52 \pm$ & .04 & 1.20 & \pm & .06 \\
\hline Iu & $0.96 \pm$ & .10 & 1.26 & \pm & .11 \\
\hline Th & 12.0 & .7 & 11.0 & \pm & .7 \\
\hline $\mathrm{Hf}$ & $8.52 \pm$ & .17 & 12.8 & \pm & .3 \\
\hline $\mathrm{Ta}$ & 2.5 & .3 & 2.2 & \pm & .3 \\
\hline $\mathrm{Mn}$ & 335 & 12 & 650 & \pm & 50 \\
\hline Co & $0.91 \pm$ & .11 & 0.34 & \pm & .13 \\
\hline $\mathrm{Fe}(q)$ & $1.17 \pm$ & .02 & 1.73 & \pm & .04 \\
\hline Sc & $3.90 \pm$ & .07 & 6.85 & \pm & .13 \\
\hline $\mathrm{Eu} / \mathrm{Sm}$ & 0.074 & & 0.134 & & \\
\hline $\mathrm{Ia} / \mathrm{Sm}$ & 5.2 & & 3.74 & & \\
\hline
\end{tabular}

After Beeson, 1969, Table II-3b and II-3d.

0-12 - Rhyolitic obsidian from west of Burns, Oregon near radar station.

0-53 - Rhyolitic obsidian from U.S. Highway 395 near Wagontire, Oregon. 
CHAPTER V

\section{DISCUSSION}

Hydration Data: Flakes

Expected Results. The expected results of an obsidian hydration analysis of this sort is a semi-continuous linear array of hydration values with occasional gaps and areas of clustering where duplication occurs. This is a numerical portrayal of a series of annual visits to a particular site, possibly year after year, for long periods of time, with short periods of abandonment. In the northern Great Basin, the last $10,000+$ years have been a time of pronounced climatic fluctuations and environmental responses. If these postulated climatic changes are indeed an accurate representation of reality in the past, then the prehistoric occupants of that area have undergone many changes in their lifeways to adapt to these changes. One aspect of their lifeways that would change in response to environmental fluctuations is site preference. The climate affects the natural resources available to a group of people in any one area. As a result, a habitation site may not always have the necessary resources available and may have been abandoned for a period of time. In the Great Basin, where many areas are marginally productive, sites were occupied annual- 
ly for many years and then abandoned. At some later point in time, a site may again be preferred and occupied for another long period in time, only to be abandoned once again. The history of a site, illustrated by a distribution of hydration data, should reflect this series of periods of occupation and abandonment. Such an illustration can result if care is taken to eliminate or minimize the types of variation that obscure the hydration rind thickness variations due to relative age differences.

Observed Results. A plot of the hydration data for both MNWR 132 (see Fig. 9) and MNWR 121 (see Fig. 10) illustrates the situation as described above. For both, the data is arrayed in a semi-continuous fashion, with occasional gaps and areas of clustering where duplication occurs. The data distribution for MNWR 121 shows fewer gaps than MNWR 132 and seems to be more continuous in nature. However, there appears to be areas of clustering that represent periods of time of repeated site occupation. The total range of the hydration values for both sites is similar, as is the interval where the greatest concentration of data points occur (approximately 4 to $7 \mu \mathrm{m}$ ). However, this may be only coincidental because the two sites are quite different in their apparent cultural functions and geomorphological and environmental settings. The magnitude of the measurements for both sites does deserve some mention. Layton 1972), in his obsidian hydration study of the cougar 
Mountain cave projectile points, reported a hydration value range of from 1.2 to $10.8 \mu \mathrm{m}$ for approximately 100 samples. The hydration value range, especially from Stinking lake site (MNWR 132), is not dissimilar from Layton's (1972), suggesting that either the obsidian artifacts at stinking Lake have been unearthed recently or they hydrate at a much slower rate than those at Cougar Mountain cave. Another interesting comparison concerns the gap in Layton's (1972) hydration "dates" between 3.4 and $3.8 \mu \mathrm{m}$. This translates to his postulated Altithermal abandonment of Cougar Mountain cave. The distribution of the stinking Lake site hydration "dates" (see Fig. 9) has a remarkably similar gap between 3.24 and $3.85 \mu \mathrm{m}$. Furthermore, the two distributions are remarkably similar throughout, with the exception of the paucity of values between 2.0 and $2.4 \mu \mathrm{m}$ at stinking Lake. A cursory comparison of both distributions shows that Layton's (1972) distribution (Fig. 16) has more duplication of values and the clusters of "dates" are more condensed, simply because his hydration values are rounded to $1 / 10 \mu \mathrm{m}$ instead of $1 / 100 \mu \mathrm{m}$. Figure 17 is a distribution of the hydration data from stinking Lake site, with all of the hydration values rounded to $1 / 10 \mu \mathrm{m}$. This distribution also appears to have more duplication of values and more condensed clusters of "dates" when compared to the distribution illustrated in Figure 9. When the View point site hydration data are rounded to $1 / 10 \mu \mathrm{m}$ (compare Fig. 18 and Fig. 10), a 


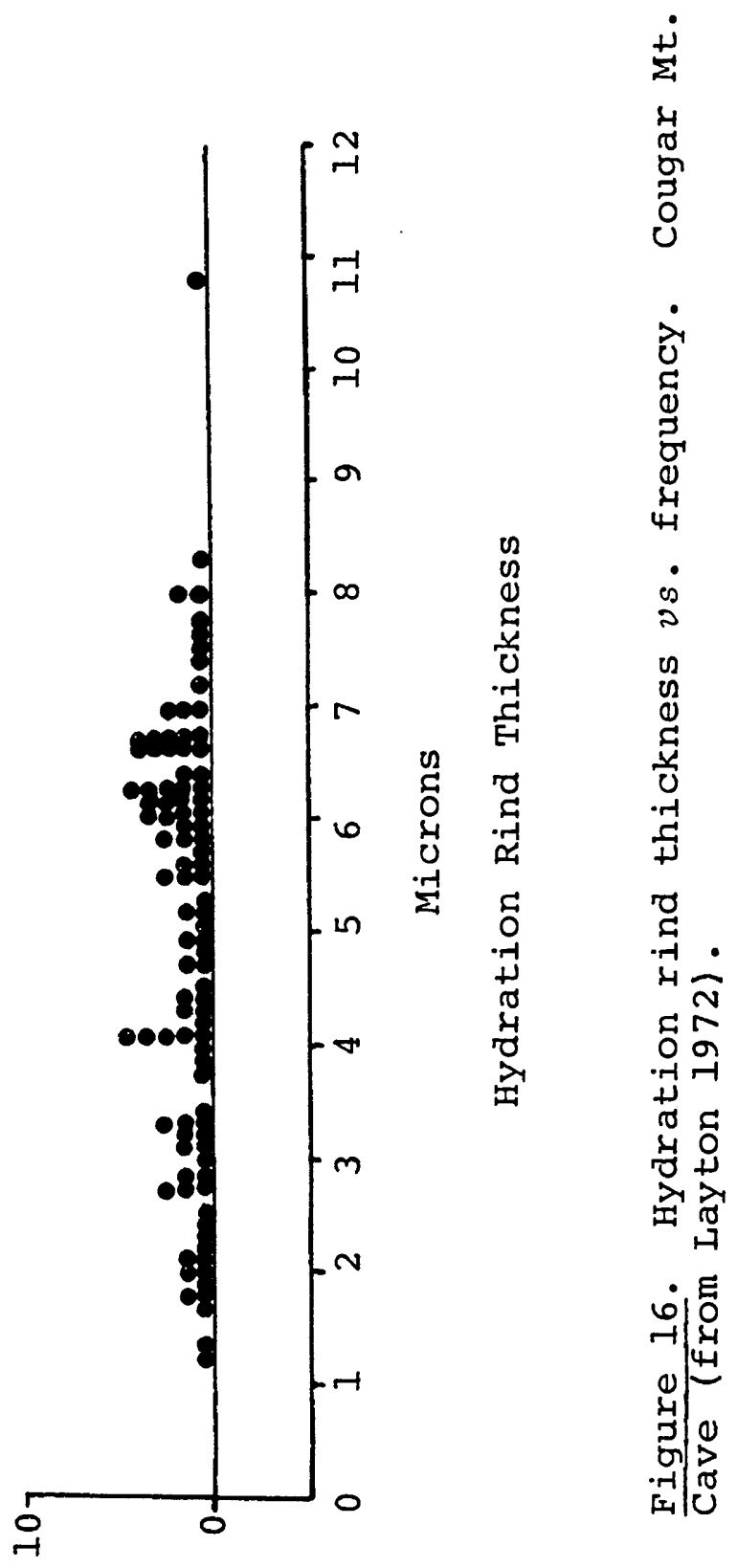

Kวนจกธอฮส 


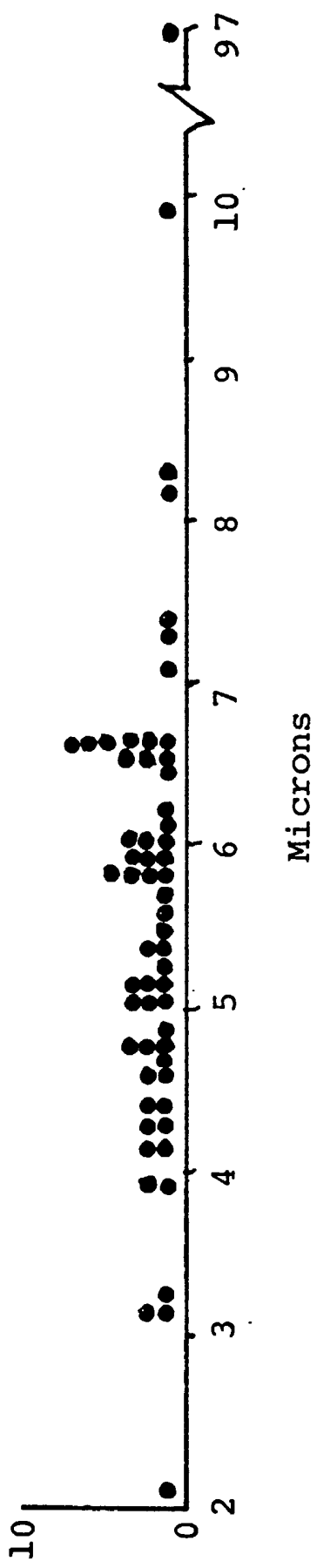

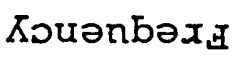

$\underset{+1}{-1}$

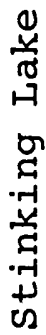

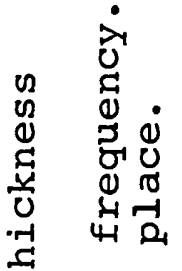

ह

'

os 0

of

\&

-

त्ञ

峁

空

号

4

今

-

ro

t

त्व

종

E

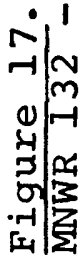




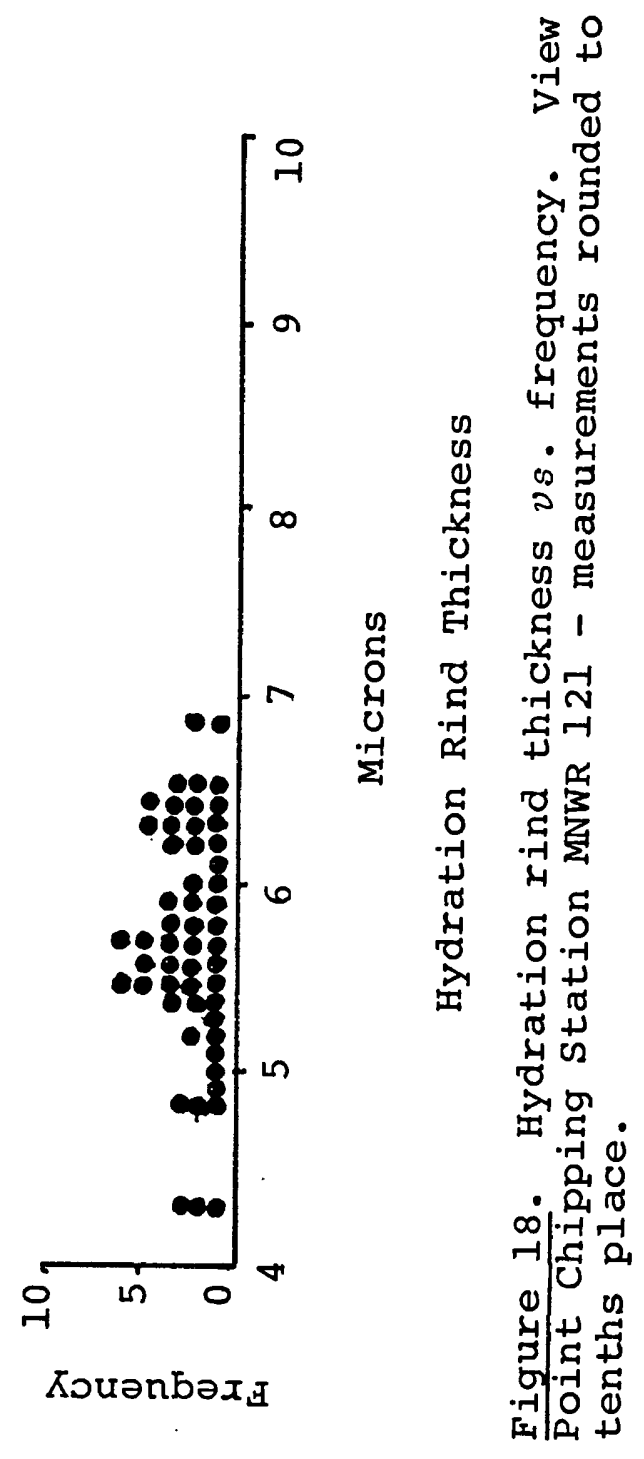


similar result occurs.

Statistical Test of the Hydration Data

Iiving site selection and occupation are non-random activities in that they are the result of cultural processes. As a consequence, an archeological site's occupational history can be seen as a series of non-random events occurring within an unspecified length of time. If the obsidian hydration data are an accurate representation of this history, a one-dimensional graphic display of these data should consist of a number of groups or single data points separated by gaps arranged in a non-random fashion along a line. I used the "one sample runs test" (Siegel 1956) to determine whether the data were arrayed in a random or non-random pattern. A "run" is a segment of a linear array of events that is composed of like events and the "runs test" is concerned with the order of those events. Each obsidian hydration data point can be considered as representing one point in time (an event) of an archeological site's history. All such data points are like events. When these hydration data points are plotted on a straight line, any point along that line where a data point occurs is considered a presence (t) event. Along this same line there are gaps between presence events, possibly indicating that the site was not occupied during these time periods. These gaps are also considered events and are referred to as absence (-) events. The following formula was 
used to compute the runs test of the two sets of data, where $\mathrm{n}_{1}=$ the number of presence $(t)$ events, $\mathrm{n}_{2}=$ the number of absence (-) events and $r=$ the number of runs (sequences of consecutive like events).

$$
\begin{aligned}
& z=\frac{r-\sigma_{r}}{\sigma_{r}}=r-\left(\frac{2 n_{1} n_{2}}{n_{1}+n_{2}}-1\right) \\
& \sqrt{\frac{2 n_{1} n_{2}\left(2 n_{1} n_{2} n_{1}-n_{2}\right)}{\left(n_{1}+n_{2}\right)^{2}\left(n_{1} n_{2}-1\right)}}
\end{aligned}
$$

(Siegel 1956)

The $r$ statistic is distributed as $z$ (normal) when either $n_{1}$ or $\mathrm{n}_{2}$ is equal to or greater than 20, which is the case with the hydration data from both sites. The null hypothesis tested in this specific case is that each set of hydration data is arrayed in a random order. A significant value for $\mathrm{z}$ suggests that the data are arrayed in a non-random fashion.

Figure 19 summarizes the results of the runs test of the hydration data from MNWR 132 and 121 . The results indicate that the $\mathrm{Z}$ value for the MNWR 132 data is highly significant $(p<<.001)$. For the MNWR 121 data the $z$ value is not significant $(p>.10)$.

Interpretation of these results is problematic. On the one hand, the runs test strongly suggests that the MNWR 132 
MNWR 132:

$$
\begin{aligned}
\mathrm{r} & =87 \mathrm{n}_{1}=722 \mathrm{n}_{2}=56 \\
\mathrm{z} & =87-\left[\frac{[(2)(722)(56)}{722+56}+1\right] \\
& \frac{\sqrt{\frac{[(2)(722)(56)][(2)(722)(56)-778]}{\left[(778)^{2}\right](777)}}}{4.84 * ; \mathrm{p}(\mathrm{z}=4.84)<.0002}
\end{aligned}
$$

*Significant at the $\alpha=.05$ level.

MNWR 121:

$$
\begin{aligned}
& r=75 \mathrm{n}_{1}=207 \mathrm{n}_{2}=42 \\
& \mathrm{z}=75-\left[\frac{\left[\frac{(2)(207)(42)}{207+42}+1\right]}{\sqrt{\frac{[(2)(207)(42)][(2)(207)(42)-249]}{\left[(249)^{2}\right](248)}}}=\right. \\
& 1.175 * * ;(\mathrm{z}=1.175) \stackrel{\text { 㸺 }}{=} .12
\end{aligned}
$$

**Not significant at the $\alpha=.05$ level.

Figure 19. Runs test computations and results fOr MNWR 132 and MNWR 121 data. 
data are non-random and apparently reflect a series of cultural events. On the other hand, the MNWR 121 data appear to be random and may not accurately represent a series of cultural events. This discrepancy between the two sets of data can be explained in terms of the length of the linear array (i.e., the number of total units) that is tested. The total number of units in the MNWR 132 array is 778, while for the MNWR 121 data it is 249. However, for both data sets the majority of hydration values (i.e., presence events) lie between 4.20 and 6.50 microns, possibly illustrating similar site occupation histories. The data array for MNWR 132 is non-random because, in addition to the concentration of data points between 4.20 and 6.50 microns, it has a few outlying data points well below and above these values (see Fig. 7). Conversely, the MNWR 121 data are restricted to a more confined array length and appear to be randomly distributed (see Fig. 9). This inherent flaw in the runs test is analogous to the one encountered with the "nearest neighbor" test. The length or area in which data points are distributed affects the results of these tests. Figure 20 is a graphical illustration of this problem. In conclusion, the runs test is affected by the length of the linear array and it may indicate misleading results when a shorter series of data points (MNWR 121 data) possibly represents a part of a larger series (MNWR 132 data). 


Absence of a Measureable Hydration Rind

The absence of measureable hydration rinds occurred with thin sections made from obsidian that had a large density of inclusions such as bubble tracks, banding patterns and microcrystallites. It is possible that either the obsidian was too opaque for the hdyration rind to be visible or the obsidian was completely hydrated and did not possess a rind. Most of the local obsidian that is available in the vicinity of the sites is derived from extensive volcanic tuffs. The obsidian shards and cobbles present in this tuff (the Danforth Formation) may be hydrated during the cooling process or before weathering out (Beeson 1979). Completely hydrated obsidian, or perlite, is suitable for artifact manufacture, although it is more fragile than nonhydrated obsidian. It is conceivable that a small number of perlite samples were collected for the hydration analysis and produced no results.

Presence of Two Hydration Values

A small number of samples (9) yielded two different hydration values. This fact suggests either artifact reuse or wind abrasion. Table IV lists the samples that demonstrated one of the two phenomena. One sample, V.P.P. I, was excluded from the examples because its two hydration values were based upon one measurement each and therefore unreliable. Artifact reuse is characterized by a large hyc̈ration value difference between two or more surfaces on the 


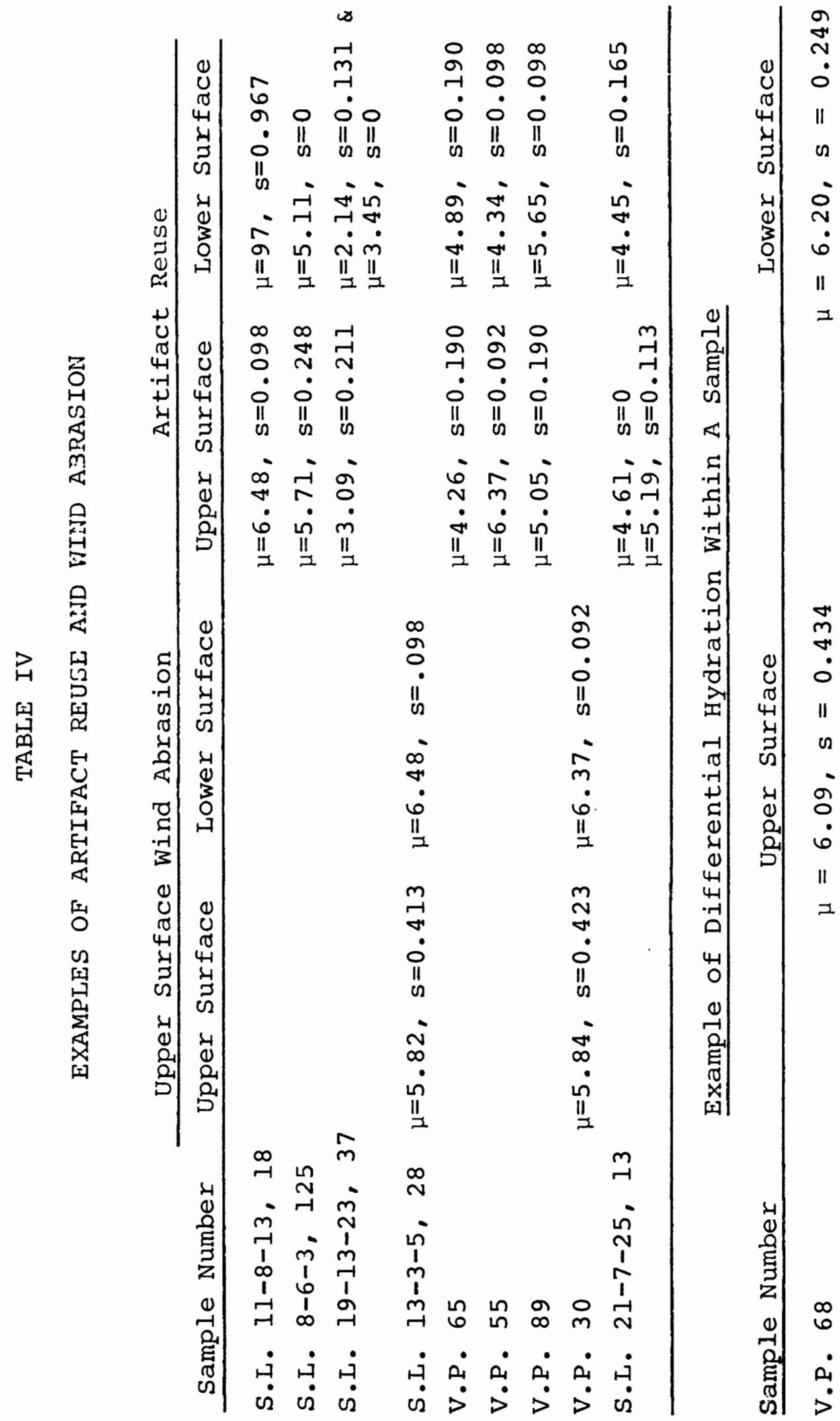


artifact and a minimal standard deviation for each. Seven of the nine examples have these characteristics and are considered examples of artifact reuse. S.L. 11-8-13, 18 is an exceptional case. The extraordinarily large hydration rind on its lower surface is probably a measure of the elapsed time since it was eroded out of its source. This reading was taken from a flake that was pitted and smoothed on one side and completely flaked on the other. At the center of the pitted surface one flake had been removed. It was this location that produced a value of $97 \mu \mathrm{m}$, while the opposite surface produced a value of $6.48 \mu \mathrm{m}$, a record of a cultural event. Although this case is not a bona fide example of artifact reuse, its characteristics are the same and it is classed as such an example. Hydration rind wind abrasion is characterized by a smaller rind thickness at the flake's upper surface and a moderately large (over $0.3 \mu \mathrm{m}$ ) standard deviation associated with it. S.L. 13-3-5, 28 and V.P. 30 possess these characteristics and are considered to be examples of the wind abrasion process.

Large Variation of Hydration Values Within an Artifact

One other process that may yield great variation in hydration values within a sample is a differential hydration rate caused by the artifact's orientation with respect to the sun, its shape or thickness. Differential hydration would be characterized by nearly equal average hydration values for all surfaces but a large standard deviation as- 
sociated with each (indicating a large amount of width variation on any one surface). One such example is V.P. 68 (Table IV), where the upper and lower surfaces yielded nearly equal hydration values, but the standard deviations were reasonably large for both. Although possibly a minor factor, differential hydration does not appear to be a major problem in studies of this kind.

\section{Index of Refraction}

Projectile Points. The two projectile point bases or stems (S.L.P. 6 and S.L.P. 7) from MNWR 132 are considered to be roughly contemporaneous because they are quite similar in their conformation and size. However, their hydration rind widths differ by approximately $2.2 \mu \mathrm{m}$, a large difference. For this reason, they were included in the chemical composition tests in order to determine if their hydration rind width difference was due to chemical composition differences. The index of refraction values for S.L.P. 6 and S.L.P. 7 were widely different (1.496-1.498 and 1.490, respectively), which indicates a difference in major element composition, which in turn, relates to the hydration rate. The two index of refraction values indicate a relationship to the hydration rate that is the opposite of the one proposed by Friedman and Long (1976). S.L.P. 6 has an index of refraction range much higher than S.L.P. 7 and also a larger hydration value. According to Friedman and Long (1976), obsidians with higher indices of refraction tend to hydrate slower than obsidians with lower indices of refraction. If Friedman and Long (1976) are 
correct, S.L.P. 6 should have a smaller hydration value than S.L.P. 7, if they are indeed contemporary and have been affected by the same temperature conditions throughout time. Since the opposite is true, the explanation for this result cannot be stated in terms of chemical composition differences. A possible explanation for this discrepancy is that the two projectile points were affected by different temperature conditions, as illustrated in Figure 21 , Case 2 . It may be wise to eliminate the index of refraction values for the projectile points from the data for interpretation. Reasons for this proposal are not empirically founded, but make intuitive sense. An archeological site with a large amount of local obsidian would not, it would seem, likely contain more than a very small quantity of imported obsidian (i.e., obsidian transported to the site area from a great distance). If the local source is chemically homogeneous throughout, it is likely that the index of refraction measurements will also be homogeneous for this source. Thus, the only source of chemically different obsidians in a site area would be through importation. Further, finished, hafted bifaces (knives and especially projectile points) or preforms are the most likely forms in which imported obsidian would appear. Such artifacts were transported long distances because they were essential items for hunting and butchering and the types of material used for their manufacture are restricted by requirements such as workability 


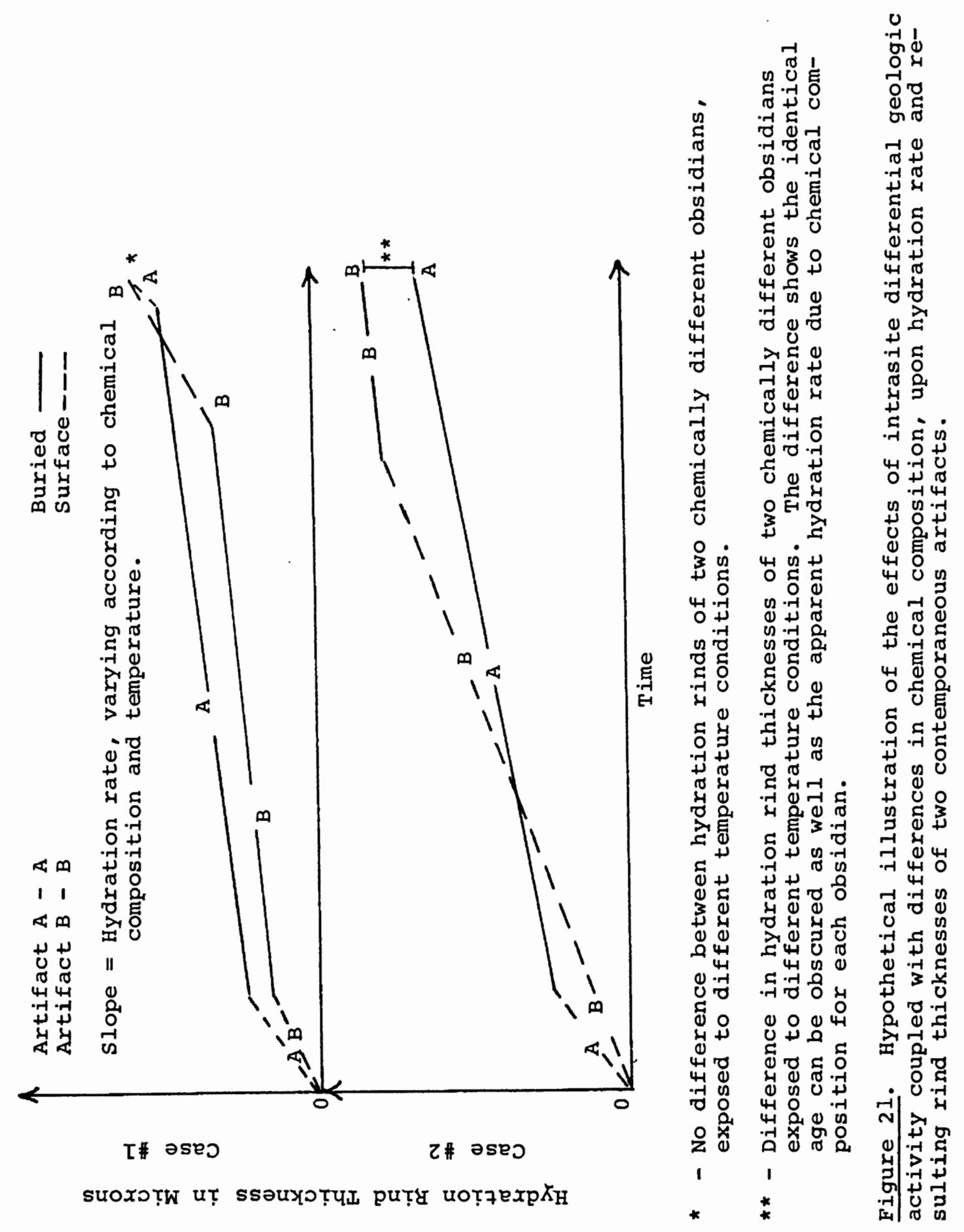


and edge sharpness. Historically, obsidian was highly regarded in that it fulfills these requirements more adequateIy than most other lithic materials. Thus, it seems likely that projectile points or their preforms would be imported into a site from great distances and have a greater probability of being chemically different from the majority of other obsidian artifacts found at such an archeological site. Therefore, it may be reasonable to eliminate the index of refraction measurements for the two projectile points (S.L.P. 6 and 7) from consideration.

Flakes. The index of refraction results from the View Point site (MNWR 121) indicate that at least six of the seven flakes analyzed are chemically homogeneous. As such, they are likely to hydrate at the same rate if exposed to the same environmental temperature. In summary, the index of refraction results show that the hydration thickness data distribution (see Fig. 9) from MNWR 121 is not due to the presence at that site of a number of chemically different obsidian flakes.

The index of refraction results (excluding S.L.P. 6 and 7) from the stinking lake site (MNWR 132) indicate that four of the five flakes analyzed are chemically homogeneous. Therefore, it is likely that the hydration thickness data distribution (see Fig. 7) is not due to the presence at that site of a number of chemically different obsidian flakes. 
Projectile Points

Chronological Sequence by Type. Layton's (1972)

relative chronology will be used as a model for arranging the projectile points in a chronological sequence on the basis of point typology. I have selected Layton's (1972) chronology for two reasons. First, he has used two general criteria, size (weight and overall dimensions) and general mode of design, to divide his collection into four general groups of points. Size is an important criteria because New World projectile points generally diminish in mass and dimension over time from ancient to recent times. A marked reduction in mass and overall dimensions is seen at the point in time when bow and arrow technology is assumed to have diffused into an area. General mode of design refers to features such as: shape of the blank, presence of corner notches, presence of side notches, presence of a basal notch, absence of one or more of these notches, presence of a stem and shoulders, type of flaking, etc. Most of these design characteristics are intimately related to the type of hafting applied to a spear, atlatl dart or arrow. Such hafting procedures change over long periods of time with the diffusion or invention of new procedures and new means of projecting the point. Second, Layton's (1972) collection contains many examples of projectile points that have been analyzed in this study. The fluted point (S.I.P. 1) and Great Basin transverse point (S.I.P. 11) are the only two 
that receive no attention from him and their positions in his relative chronology are relatively easy to determine with some supplemental help from Heizer and Hester (1978). Fagan's (1974) classification is more detailed than Layton's (1972) and some of the projectile points in this study were classified according to his scheme. However, these points can be fitted into Layton's (1972) chronology because their size and mode of design coincide with one of his chronological groupings or another.

Layton's (1972) relative chronology is divided into four large Traditions, all with long duration and overlap between them. The first, or earliest, is the stemmed Projectile Point Tradition (SPPT), that is characterized by large stemmed projectile points such as: Layton's (1972) Type 1 (Cougar Mountain type), Type 2 (Lind Coulee or Parman type) and Type 3 (similar to the scottsbluff type of the northern Great Plains). Bedwell (1970) links these stemmed points with his Western Pluvial Lakes Tradition of the Anathermal, a tradition based upon the exploitation of a series of lakes and marshes within the pluvial Lake Lahontan drainage (which includes the Harney and Malheur Basins). Following this and contemporaneous with its decline is the Lanceolate Projectile Point Tradition (IPPT), which is generally characterized by medium to large sized lanceolate points. Included in this tradition are point types such as: the Haskett type (Type 4), the Cascade type 
(Type 5), the Humboldt type (Type 7) and the Great Basin Transverse type (Heizer and Hester 1978). This tradition is Anathermal in its most ancient form, but extends into more recent times as witnessed by the long period in which Cascade type points were manufactured and used. At some time, near the onset of the Altithermal (Layton 1972), the beginnings of the Large Triangular Notched Projectile Point Tradition (LTNPPT) are seen. Layton (1972:10) equates the development of this tradition with the response to drying conditions and sees it as the beginnings of a true Desert Culture lifeway. Northern side-notched (Type 8), Elko eared (Type 6), Elko side-notched (Fagan 1974; Layton 1972, Fype 9) anc Pinto square shoulder (Eeizer and Fester 1978) projectile points are members of this tradition that occur throughout the Altithermal and until the introduction of the bow and arrow. The introduction of bow and arrow coincides with Layton's (1972) Small Triangular Notched Projectile Point Tradition (STNPPT). Many of the points that are manu factured and used during this era are patterned after points from the previous period. Size is the only great difference between the new types and old. With the introduction of the bow as a means of projecting an arrow, the mass of the projectile was drastically reduced because increased velocity was provided by the bow. Small, triangular, notched, projectile points include such types: Rose springs cornernotched (Fagan 1974, Gunther barbed (Type 10, Layton 1972), 
Surprise Valley split stem (Fagan 1974, Type 2F) and Desert side-notched (Fagan 1974, Type 3B).

Comparison of Typological Sequence and Hydration Data.

All of the points, analyzed for their hydration rind thickness, fit into one or another of Layton's (1972) four traditions (Table V), with the exception of the fluted point, S.L.P. I. Fluted points are considered by Heizer and Hester (1978) to pre-date all of the Great Basin projectile points that they described. Therefore, S.L.P. I should be considered either pre-SPPT or coeval with the earliest portion of it. A modified relative chronology was designed to include Layton's (1972) four traditions and one additional tradition, the Pre-Stemmed Projectile Point Tradition (Table V). Each of the projectile points (including the points with and without hydration "dates") was positioned in the modified relative chronology, according to their conformation and size, in one of the five traditions. Next, projectile points with hydration "dates," were arranged in the sequence that is illustrated by the plot of their hydration rind thicknesses (see Fig. 12). Finally, the two sequences were compared and any anomalous results were noted (Table $V$ ). The comparison shows that a majority of the projectile points are in their proper chronological order (as determined by their morphology and size) with the exception of one obvious (S.L.P. 7) and two less obvious (S.L.P. 10 and S.L.P. 1I) results. S.L.P. 10, classified 


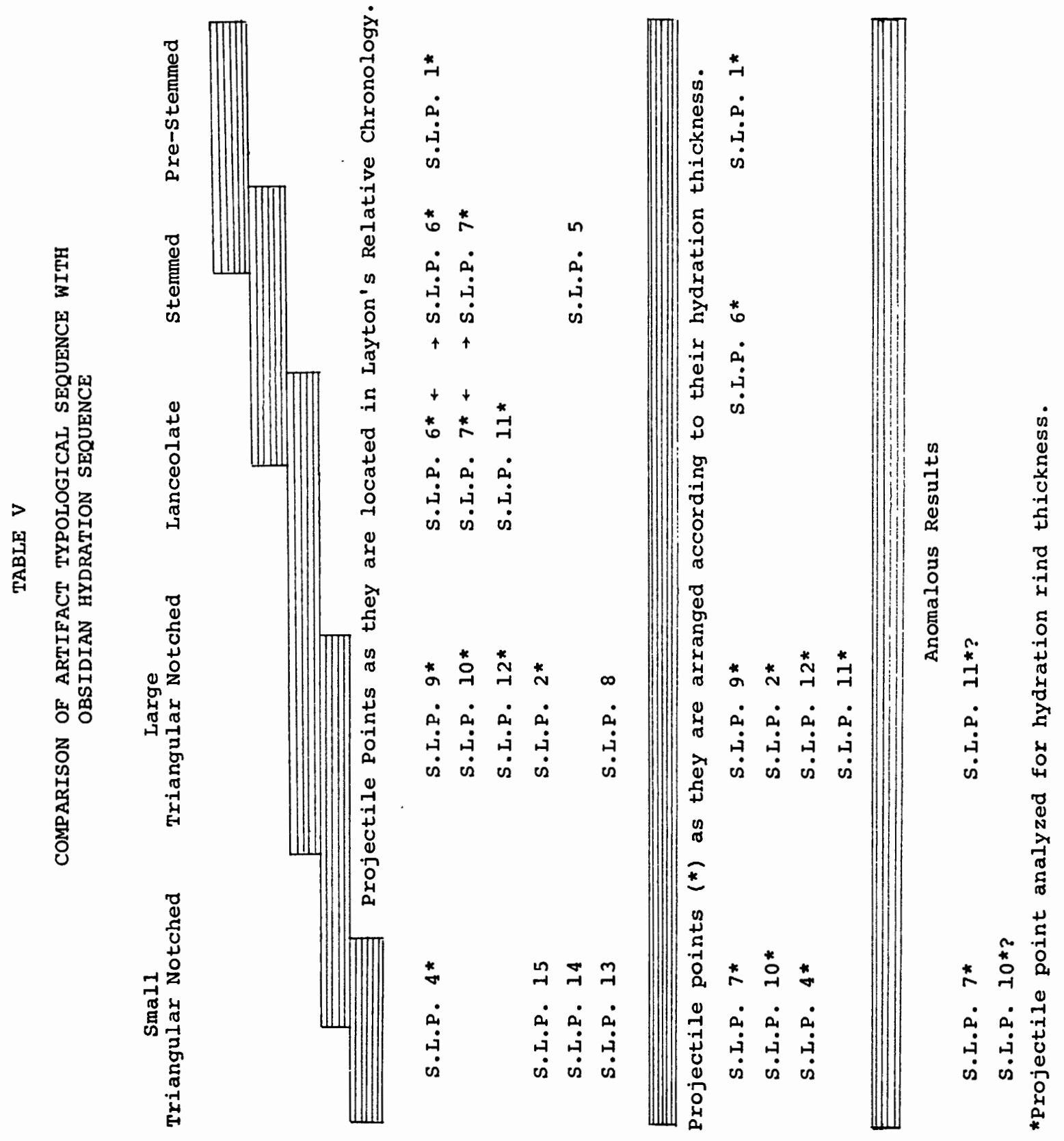


as a Pinto square shoulder type point, belongs in the LTNPPT, when in fact its hydration "date" places it in the same group with S.L.P. 4, an early form in the STNPPT. It is quite possible that S.L.P. 10 is a late member of the older tradition, since these two traditions overlap in time, and may accurately be grouped with S.I.P. 4 as an early form of the more recent tradition. A similar case can be stated for S.L.P. 11. It is coeval with lanceolate forms of projectile points (Black Rock concave base) and is considered early (Heizer and Hester 1978). Its hydration "date" (see Table V) places it in the middle of a group of points belonging to the TNPPT. It is possible that S.L.P. Il may be a late form of the Great Basin Mransverse type because the two traditions overlap. S.I.P. 7, on the other hand, is definitely an anomalous result. As discussed above, the relationship between hydration rind thickness and index of refraction (in the special case of S.L.P. 6 and 7) indicates that the anomalous hydration thickness value for S.L.P. 7 is not due to chemical composition differences, but to the effects of a different environmental temperature. For whatever reasons, S.L.P. 7 is the only obvious departure from the relative chronology produced by the projectile point hydration data.

The projectile point hydration data from View Point chipping station (MNWR 121) are too incomplete to substantiate the flake hycration data. Three points were collected when 
the site was first surveyed in 1974, but two were unsuitable for my study because they were manufactured from materials other than obsidian. The third, V.P.P. I, an Elko eared point, produced two hydration values $(6.26$ and 8.89 $\mu \mathrm{m})$, neither of which is reliable, because they are derived from one measurement each. V.P. 62, collected during my field survey in the fall of 1978, produced no measureable hydration rind. As a result, neither of the two points provide any substantive evidence. 


\section{CHAPTER VI}

\section{SUMMARY AND CONCLUSIONS}

The index of refraction results reveal that all of the flakes had closely similar indices of refraction, which in turn indicates that their major element compositions were also similar. This means that the sample flakes have similar, if not the same, hydration rates, if exposed to the same temperature conditions. One can then be reasonably conclusive that the chronological orderings, produced by hydration data distributions from MNWR 132 and MNWR 121, are a result of relative age differences and possibly differential temperature condition, not variable chemical composition.

Index of refraction data, derived from the two projectile points stems (S.I.P. 6 and S.I.P. 7), indicates that they have markedly different major element chemical compositions and if exposed to identical temperature conditions, would hydrate at different rates. As discussed (see Index of Refraction Results) above, it is possible that projectile points, as a functional group of artifacts, may have a greater probability of being chemically different from the majority of obsidian debitage at an archeological site, where extensive deposits of chemically homogeneous, 
local obsidian are available. Therefore, a chronological ordering, derived solely from the hydration values of projectile points, is not as reliable as one produced by flakes. Fortunately, projectile points are, in most cases, cultural time markers and it is possible to refer to artifact classifications and typologically produced chronologies to double check their hydration values. In summary, the combination of flake and projectile point hydration data will, in most cases, yield satisfactory results.

Such is the case of the projectile point hydration data for stinking lake site (MNWR 132). The points were classified and arranged in their chronological order by type, with the aid of three studies that pertained to the northern Great Basin. These results were compared to the hydration value, chronological ordering. With the exception of possibly three, the projectile points were arranged in a reasonably good chronological order as a result of their age differences. As discussed in the Index of Refraction Results Section, S.L.P. 7 had a relatively "young" hydration date that is explained by the exposure to differential temperature conditions. S.L.P. 10 and S.L.P. 11 also had relatively "young" hydration dates. It is possible they are recent representatives of the type of projectile points in which they were classed. It is also possible that they hydrated relatively slow, when compared to the rest of the projectile points, because they were chemically 
different and/or exposed to lower temperatures.

At Stinking Lake Site (MNWR 132) the projectile point hydration data, the chemical composition data and the flake hydration data illustrate that a relative chronology can be generated for a surface site using the obsidian hydration dating method. Concerning View Point Chipping station (MNWR 121), the data are not conclusive, because there is no projectile point hydration data to support the flake hydration values and distribution. However, considering the chemical composition homogeneity of the samples and the lack of large geomorphological variation over the site area, the hydration data should be considered a reasonably accurate relative chronology.

As with any study, many questions are raised during the process of attempting to answer the original one. Further work in the realm of hydration dating, as applied to surface archeological sites, is necessary to produce more accurate, reliable results. An in depth study of the geomorphological processes occurring in a site area, as well as predictions of past processes is needed to better understand, estimate and control the effects upon obsidian artifacts of differential temperature conditions. Relative chronologies will be much more secure if the hydration data from different sectors of a site can be adjusted for these effects. In future work it will be necessary to apply more rigorous chemical composition analysis methods. Initially, the trace 
element composition must be known to assess the chemical homogeneity within the samples. Instrumental Neutron Activation Analysis (INAA) can be used to accomplish this task and will aid in determining source areas for the samples. $x$-ray fluorescence analysis, a method of determining the major element composition of obsidian, is needed to interpret the hydration data, once their chemical homogeneity or lack thereof is known. As the major element composition is directly linked to the hydration process, the rate of hydration for each chemically different obsidian sample can be determined. Combined, the two techniques can be a powerful tool, needed to fully understand and interpret hydration data and distributions. Adjunct to this work, is the need for work on the relationship between the hydration process itself and the chemical composition of the obsidian. Until the obsidian hydration process is fully understood, chemical composition analyses are not as powerful as they might be as interpretive tools. 


\section{BIBLIOGRAPHY}

Aiello, P.

1969 The Chemical Composition of Rhyolitic obsidian and Its Effect on Hydration Rate: Some Archeological Evidence. Masters Thesis, Dept. of Anthropology, U.C.L.A.

Bedwell, S.

1970 Prehistory and Environment of the Pluvial Fort Rock Area of Southcentral Oregon. Ph.D. Dissertation, Dept. of Anthropology, Univ. of Oregon, Eugene, Or.

Beeson, $M$.

1969 A Trace Element Study of Silicic Volcanic Rocks. Ph.D. Dissertation, Dept. of Geology, Univ. of Calif., San Diego.

Beeson, $M$.

1979 Personal communication.

Bloss, D.

1961 An Introduction to the Methods of optical Crystallography. Holt, Rinehart and Winston, New York.

Bowman, H. R., F. Asaro, and I. Perlman

1973 Composition Variations in Obsidian sources and the Archaeological Implications. Archaeometry 15(1): $123-127$.

Butler, B. R.

1964 A Recent Early Man Point Find in Southeastern Idaho. Tebiwa $7(1): 39-40$.

Ericson, J.

1978 Advances in Obsidian Glass Studies: Archeological and Geochemical Perspectives. R. E. Taylor (ed.), Noyes Press, Park Ridge, N. J.

Ericson, J. and J. Kimberlin

1977 Obsidian Sources, Chemical Characterization and Hydration Rates in West Mexico. Archaeometry 19(2): 157-166. 
Fagan, J.

1974 Altithermal Occupation of Spring Sites in the Northern Great Basin. Univ. of Oregon Anthropological Papers No. 6 .

1975 Obsidian Hydration Analysis of Three Sites in Western Oregon. Univ. of Oregon Anthropological Papers ijo. 8.

Friedman, I. and R. I. Smith

1960 A New Dating Method Using Obsidian: Part I, The Development of the Method. American Antiquity $25(4): 476-522$.

Friedman, I. and W. Long

1976 Hydration Rate of Obsidian. Science (191): $347-352$.

Heizer, R. and T. Hester

1978 Great Basin Projectile Points: Forms and Chronology. Ballena Press Publications in Archeology, Ethnology and History. Io. Io.

Hester, T., R. Heizer and J. Graham

1975 Field Methods in Archaeology. Mayfield Press,
Palo Alto.

Johnson, L., Jr.

1969 Obsidian Hydration Rate for the Klamath Basin of California and Oregon. Science (165): 1354-1356.

Katsui, $Y$. and $Y$. Kondo

1978 Advances in Obsidian Glass Studies: Archeological and Geochemical Perspectives. R. E. Taylor (ed.), Noyes Press, Park Ridge, N. J.

Kelly, M.

1979 Personal Communication.

Layton, $\mathrm{T}$.

1972 Lithic Chronology in the Fort Rock Valley, Oregon: An Obsidian Hydration Study from Cougar Mountain Cave. Tebiwa 15(2): 1-22.

1973 Temporal Ordering of Surface Collected Artifacts by Hydration Measurements. Archaeometry $15(1): 129$. 
Meighan, C., L. Foote, and P. Aiello

1965 Obsidian Dating in West Mexican Archeology. Science (160): 1069-1075.

1978 Advances in obsidian Glass Studies: Archeological and Geochemical Perspectives. R. E. Taylor (ed.), Noyes Press, Park Ridge, N. J.

Newman, T.

1974 Unpublished Report of the 1974 Malheur National

Wildife Refuge Archeological Field school.

Siegel, S.

1956 Nonparametric statistics for the Behavioral Sciences. McGraw-Hill, New York.

Thomas, D.

1976 Figuring Anthropology: First Principles of Probability and Statistics. Holt, Rinehart and Winston, New York. 


\section{APPENDIX A}

Projectile Points: Classification

Great Basin Projectile Points: Forms and Chronology (Heizer and Hester 1978), is a general classification and temporal ordering of the major projectile point types found in the Great Basin. In this work the authors have attempted to synthesize a large body of data dealing with the geographical and temporal ranges of major types of projectile points. The temporal ranges are derived from Carbon-14 dates. Layton (1972), in his work on the Cougar Mt. Cave artifacts, deals solely with hydration measurements for his age determinations and temporal ordering. Fagan (1974) cieals with a large variety and number of projectile points in his study of several spring sites in the Malheur Basin of southeast oregon. He employs a more detailed classification than either Heizer and Hester (1978) or Layton (1972) and arranges the resultant types in a general chronology for the Malheur Basin. The chronology is based upon Carbon-14 dating and stratigraphic correlations. I found Layton's (1972) and Fagan's (1974) classification more valuable than Heizer and Hester's (1978) in classifying my projectile points, because the types described and illustrated in these works showed great similarity to the projectile points in 
this study. This was possibly due to the fairly restricted geographic area Layton (1972) and Fagan (1974) were dealing with and its nearness to my area of study. The chronologies described in these three works are reasonably similar to one another, with Heizer and Hester's (1978) being the most conservative in terms of postulated antiquity. Layton's (1972) chronology, derived from obsidian hydration data, should be applied with caution because he did not attempt to determine the chemical homogeneity of his sample. Nonetheless, it is derived from a large sample (100 projectile points) and the relative positions of the different types of points in his chronology can be considered fairly accurate. In the following artifact classifications and chronological ordering, all three works were consulted at one time or another. Stinking Lake Site (MNWR 132), a site rich in lithic debris, has yielded a moderately large surface collection of projectile points. Fourteen were illustrated and classified and eleven were analyzed for their hydration thickness for the present study (see Table V).

S.L.P. $10(4.11 \mu \mathrm{m})$ is a medium size projectile point made on a triangular blank with straight sides. It has extremely well developed barbs produced by deep corner notches and a well defined basal notch. It appears to be quite similar in conformation to a variety of the Pinto square shoulder point as described by Heizer and Hester (1978). A temporal span of 5000-2700 BP is indicated by 
them to be the length of time in which the Pinto series was in use. S.L.P. 10 is included in Layton's (1972) Large Triangular Notched Projectile Point Tradition (8500-2100 BP) which includes the same group of projectile points as does Fagan's (1974) Period III (7000-5000 BP).

S.L.P. $7(4.22 \mu \mathrm{m})$ is a point base that was apparently derived from either a large stemed point with sloping or squared shoulders or a lanceolate point. This type of point was not discussed in Heizer and Hester (1978) but was included in Layton (1972) and Fagan (1974). In Layton's (1972) classification this point base would be included in his Type 3 or Type 4 grouping. Type 3 is characterized by square, straight based stems, squared or slightly sloping shoulders and is considered to be quite similar to the scottsbluff projectile points from the northern Great Plains. Type 4 is characterized by a slightly concave or convex base and a lanceolate form and is considered to be similar to the Haskett Type 1 of Butler (1964). S.I.P. 7 would be included in Fagan's (1974) Type 6A or Type 5A. Type 6A includes large stemmed points and knives without shoulders and Type 5A includes large, stemmed points and knives with shoulders. Layton's (1972) Type 4 points are included in his Lanceolate Projectile Point Tradition (12,500-3240 BP) and Type 3 points are included in his stemmed Projectile Point Tradition (13,000-8500 BP). Both Type 5A and 6A of Fagan (1974) are included in his Period IV (11,000-7000 BP). 
S.I.P. $4(4.36 \mu \mathrm{m})$ is similar in size and conformation to the smaller forms of the Elko eared type projectile point in both Heizer and Hester (1978) and Layton (1972). However, one feature of S.L.P. 4 that is slightly aberrant is the poorly defined corner notches. Its barbs are quite small relative to most Elko eared specimens. Although difficult to measure because of its fragmentary nature, S.I.P. 4 seems to be somewhat smaller than the average dimensions of other Elko eared specimens. At any rate, it should be considered to have been manufactured near the end of the time span when the Elko eared projectile point was in use. This would be the latter part of Heizer and Hester's (1978) 40001500 BP time span or at the end of Layton's (1972) Large Triangular Notched Projectile Point Tradition (8500-2100 BP) - S.L.P. 4 showed great similarity to Type 2E in Fagan (1974) which is a member of the triangular shaped, cornernotched point group that includes the Elko corner-notched and Rose Springs corner-notched type projectile points. These are differentiated from the Elko eared type because they are considered to have either a straight or concave base instead of an obviously notched base. It is possible that S.I.P. 4 fits more comfortably into the Type $2 \mathrm{E}$ group of artifacts because of its concave base. Type $2 \mathrm{E}$ projectile points were used during Period I (3000-1500 BP) of Fagan's (1974) chronology. In any case, S.L.P. 4 is a fairly small, triangular, corner-notched, concave base pro- 
jectile point of fairly recent origin.

S.I.P. $9(5.09 \mu \mathrm{m})$ is a fairly long, narrow projectile point that has small side notches and a straight base and sides. It is similar to the Northern side-notched projectile point, as defined and illustrated in Heizer and Hester (1978) but lacks the marked concave base that most Northern side-notched points exhibit. It is quite similar to Layton's (1972) Type 9 which is similar to the Northern side-notched (Type 8), but lacks its concave base, accentuated side notches and breadth. As a result, S.L.P. 9 should be considered a member of the group of projectile points possessing the same characteristics as Layton's Type 9 which is included in his Large Triangular Notched Projectile Point Tradition (8500-2100 B.P.)

S.L.P. $2(5.27 \mu \mathrm{m})$ is most similar to the Elko eared variety of projectile point, made from a large triangular blank, corner-notched with moderately large barbs, notched base and slightly concave on the sides from base to tip. Heizer and Hester (1978) place the Elko eared type in the time range from 4000-1000 B.P., whereas Layton (1972) would place it in his Large Triangular Notched Projectile Point Tradition that has a range from 8500 to 2100 B.P. Fagan (1974) would place the Elko eared type in his Period III that had a duration of 2000 years, from 7000 to 5000 B.P. S.L.P. $11(5.41 \mu \mathrm{m})$ is classified as a Great Basin Transverse projectile point or, more commonly, a "crescent." 
It is represented in this instance by one half of a complete point, was transversely hafted instead of longitudinally as with other projectile points and is thought to have been used to hunt waterfowl (Heizer and Hester 1978). Considered by some investigators to be a time marker for early sites in the Great Basin, the "crescent" is Anathermal (pre-Altithermal) in age and coeval with large concave base projectile points, such as the Black Rock concave base type (Heizer and Hester 1978). They postulate that the "crescent" point was commonly used in the Great Basin during the time span from 9000 to 8000 B.P., although they are reported from Connley Caves, Oregon as early as 13,000 B.P. (Bedwell 1970). Neither Layton (1972) nor Fagan (1974) report the chronological position of the Great Basin Transverse projectile point. S.L.P. $12(5.9 \mu \mathrm{m})$ was found to be most similar in conformation and size (estimated) to the Northern sidenotched type projectile point. It is also apparent that it was reused as a scraper because the lateral edge, where a portion of the point was broken off, has been steeply retouched and shows evidence of use. The reutilization of this point probably occurred roughly contemporaneous with its original manufacture, because the hydration rind measurements are quite similar on all surfaces (the rind thickness average, $u=5.9 \mu \mathrm{m}, \mathrm{s}=0.124$ and $\mathrm{n}=6)$. According to Layton (1972), the Northern side-notched type 
point is part of the Large Friangular Notched Projectile Point Tradition (8500-2100 B.P.). Heizer and Hester (1978) report 5400 B.P. as the most likely date for the ivorthern side-notched point, while Fagan (1.974) would include it in his Period III (7000-5000 B.P.).

S.I.P. $6(6.48 \mu \mathrm{m})$, very similar to S.L.P. 7, is the stem (or base) of a large projectile point with sloping or square shoulders or a lanceolate form. It is broader at the base, less finely flaked than S.L.P. 7 and has a moderate anount of crushing along its eciges. Layton (1972) notes that none of the Type 3 (Scottsbluff like) points had any evidence of grinding on the edges of the stems, whereas Type 4 (Haskett like) points generally exhibit crushed or slightly ground eages near the base. Using edge grinding or crushing as a category, it might be possible to classify S.I.P. 6 as a Type 4 (Haskett like) point and S.L.P. 7 as a stemmed point (Type 3), similar to scottsbluff points of the northern Great Plains. However, both are too incomplete to base their classification on the presence or absence of edge grinding or crushing. Therefore, S.L.P. 6 should be considered to have approximately the same chronological position as S.L.P. 7 .

$$
\text { S.L.P. I }(8.45 \mu \mathrm{m}) \text { is a nearly complete, fluted, }
$$

lanceolate projectile point. Although fairly small, it is fluted on both sides, with the flute scar on one side extending from the base to the tip. Very little is known of 
the fluted point in the northern Great Basin, as most specimens are incomplete and no buried, datable specimens have been excavated. S.L.P. I is finely flaked (in an oblique manner) with the surface of one side almost obliterated by the removal of the fluting flake. Fluted points were not described or incorporated into the classifications of either Layton (1972) or Fagan (1974). Heizer and Hester (1978) report the scanty finds of fluted points in the Great Basin and offer a few illustrations, none of which remotely resemble S.L.P. 1. They note that fluted points are considered to be the most ancient of the projectile point types used in the Great Basin and propose that they are pre-12,000 B.P. in age.

S.L.P. 8 (no rind observed) is a large unfinished, side-notched point that is most similar to a Northern sidenotched type, as defined by Heizer and Hester (1978), Fagan (1974) and Layton (1972). According to the chronologies reported by all four of the authors, S.L.P. 8 was probably manufactured 5000 years ago.

S.L.P. 5 (no rind observed) is the base of a large concave base point. Judging from the conformation of the base, it is most similar to Fagan's (1974) Type 7C, which is characterized as a stemmed, indented base point. Type 7C is positioned in Period IV (11,000-7000 B.P.) of his chronology.

S.L.P. 13 (not analyzed) is a small stemmed projec- 
tile point that is quite similar to Heizer and Hester's (1978) Rose springs contracting stem type, only considerably larger. It should most likely be included in Type 5A of Fagan's (1974) classification. Type 5A is characterized as small, broad, stemmed points and knives with shoulders and is placed in Period I (3000-150 B.P.) of his chronology. S.I.P. 14 (not analyzed) is a small corner-notched point made from a triangular blank, most similar to the Rose spring corner-notched type as described by Heizer and Hester (1978). They suggest 1400-900 B.P. as a likely time span for the use of this projectile point type. S.I.P. 15 (not analyzed) is a small, triangular, corner-notched point with an indented base and lenticular cross section. It was described and photographed during my field work in the fall of 1978. Its size and conformation closely resemble Fagan's (1974) Type 2F, which he likens to the Surprise valley split stem type. He places this type into his period I (3000-150 B.P.).

only two obsidian projectile points were available for hydration analysis from View point Chipping station. One of these was collected in 1974 by the Archeological Field school survey team, under the supervision of Dr. Thomas Newman. The specimen is part of a large collection of artifacts from various sites on the Malheur National Wildife Refuge that are housed at Portland state University. The second specimen was inadvertently collected in 
the fall of 1978 when my field work was undertaken. Neither of the two projectile points provided reliable hydration rind measurements.

V.P. 62 (no rind observed) is the basal portion of a large basal-notched projectile point. It appears to have been lanceolate, without noticeable stem or edge grinding. V.P. 62 is most similar to the Humboldt concave base type point as described and illustrated by Heizer and Hester (1978) and Fagan (1974). Fagan's (1974) classification tends to be more specific in detail and provides more examples of each type. This allowed me to differentiate between the $A$ and $B$ varieties of the Humboldt concave base type point. V.P. 62 should be included in the A variety, which tends to be larger than the B variety. Heizer and Hester (1978) report a 6000 to 3000 B.P. time span for the Humboldt type projectile point while Fagan (1974) includes them in his Period IV (11,000-7000 B.P.).

V.P.P. I produced two hydration measurements, 6.26 and 8.89 microns, neither of which should be considered reliable, as they are derived from only one measurement each. It is a triangular, corner and basally notched, projectile point of similar size and shape to S.I.P. 2 . It is most similar to the Elko eared type point that has been given various different time ranges, as discussed above. Heizer and Hester (1978) report a time span of 3000 years (4000-1000 B.P.), Layton (1972) a range of from 
8500 to 2100 B.P. and Fagan (1974), a range of from 7000 to 5000 B.P. (Period III). 


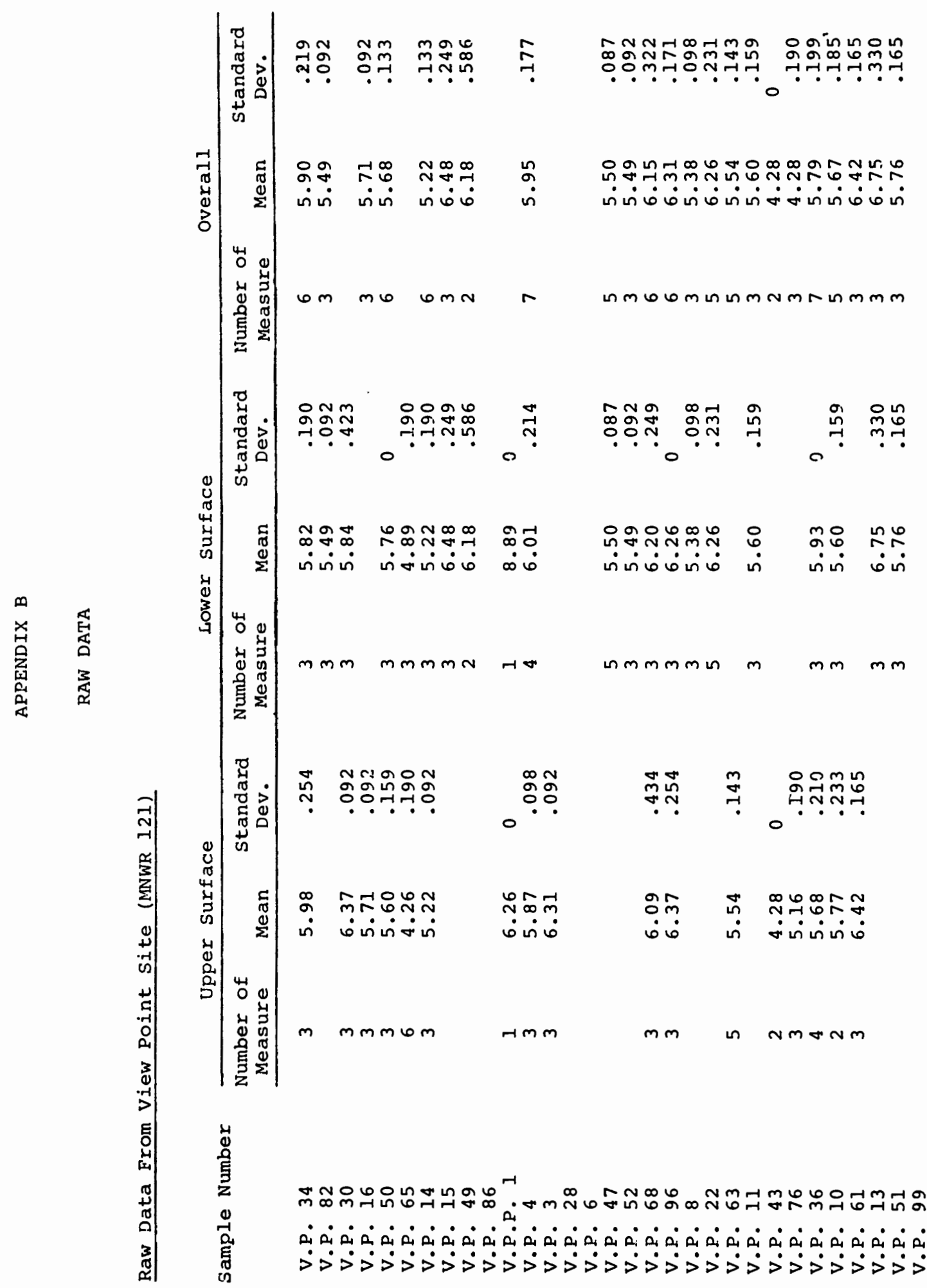




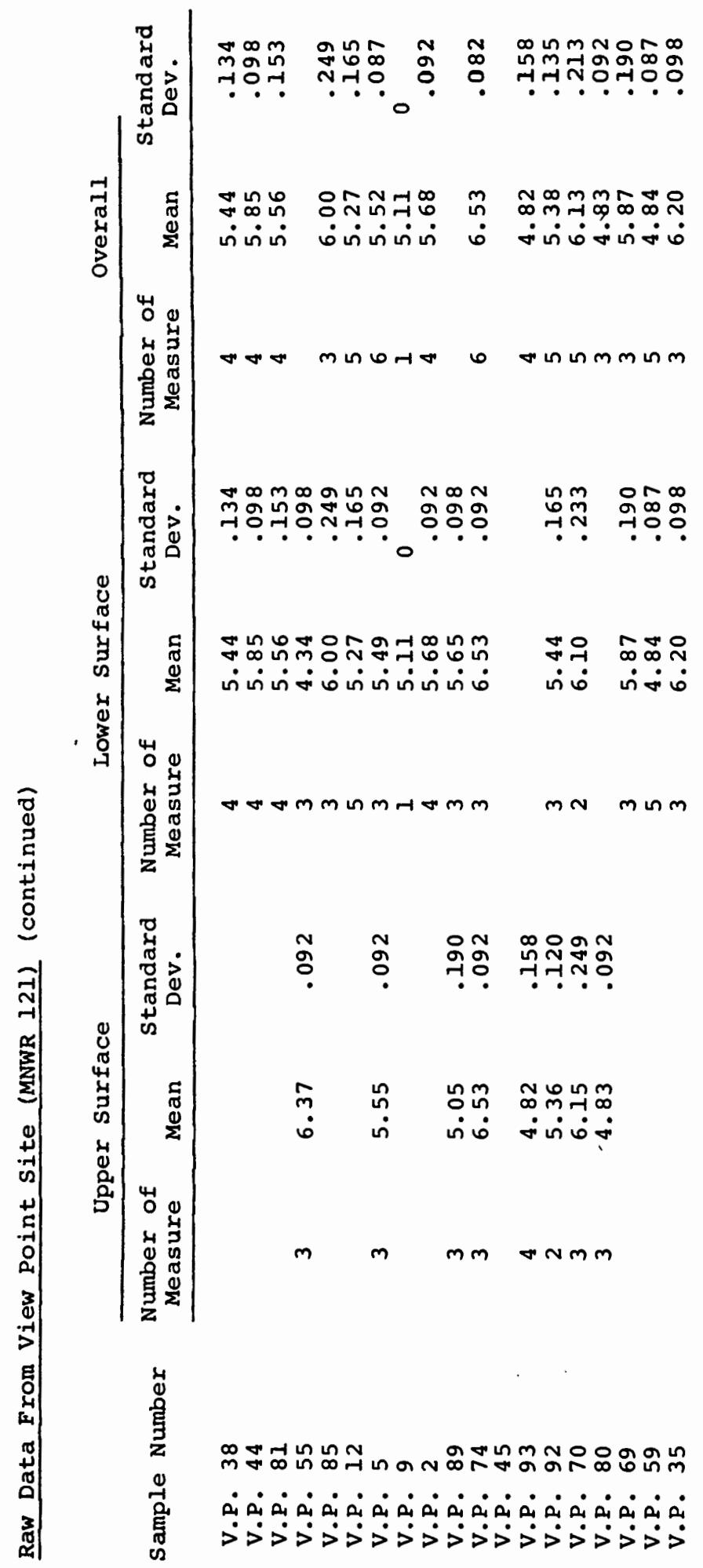




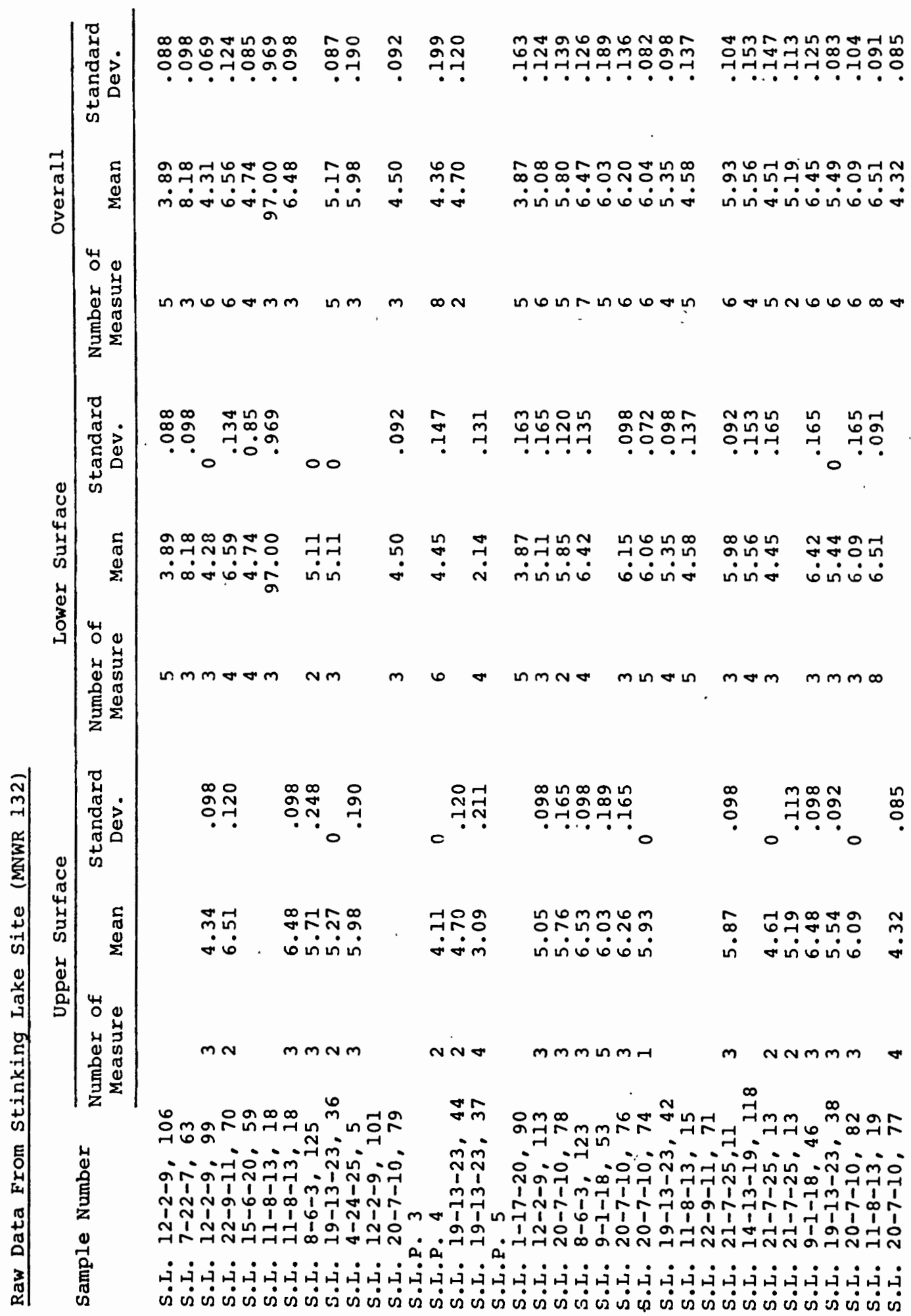




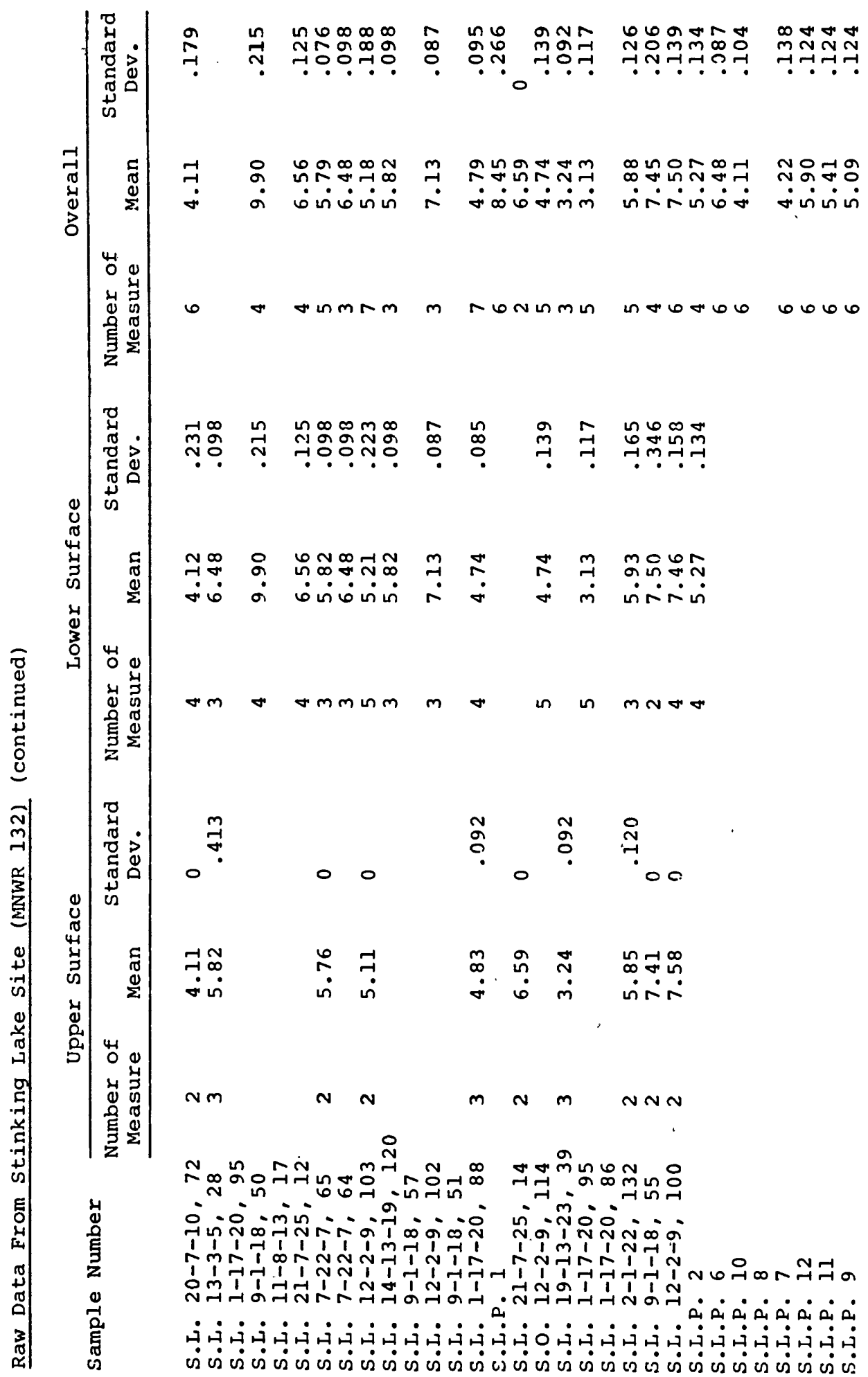

